\title{
Individual variability in the swimming behavior of the sub-tropical copepod Oncaea venusta (Copepoda: Poecilostomatoida)
}

\author{
Laurent Seuront ${ }^{1,2, *}$, Jiang-Shiou Hwang ${ }^{3}$, Li-Chun Tseng ${ }^{3}$, François G. Schmitt ${ }^{1}$, \\ Sami Souissi ${ }^{1}$, Chong-Kim Wong ${ }^{4}$ \\ ${ }^{1}$ Ecosystem Complexity Research Group, Station Marine de Wimereux, CNRS UMR 8013 ELICO, Université des Sciences et \\ Technologies de Lille, 28 avenue Foch, 62930 Wimereux, France \\ ${ }^{2}$ School of Biological Sciences, Flinders University, GPO Box 2100, Adelaide 5001, South Australia \\ ${ }^{3}$ Institute of Marine Biology, National Taiwan Ocean University, Keelung, Taiwan 202, Republic of China \\ ${ }^{4}$ Department of Biology, The Chinese University of Hong Kong, Shatin, Hong Kong, China
}

\begin{abstract}
The swimming behavior of males and females of the seldom studied sub-tropical copepod Oncaea venusta was studied using scale-dependent (swimming speed and net-to-gross displacement ratio) and scale-independent (fractal dimension) metrics. The scale-dependent metrics were characterized by: (1) a considerable intra- and inter-individual variability that prevented the identification of any specific behavior and (2) a strong dependence on the number of data points available in each individual path. Conversely, the scale-independent metric (fractal dimensional) resolved reduced intra- and inter-individual variability and independence from the length of the swimming paths, leading to the identification of 4 groups of distinct swimming patterns. While additional behavioral experiments are needed to ensure the relevance and the generality of the present results, behavioral fractal analysis nevertheless demonstrates a promising ability to elucidate the complexity of zooplankton behavior.
\end{abstract}

KEY WORDS: Zooplankton $\cdot$ Swimming $\cdot$ Behavior $\cdot$ Scale-dependence $\cdot$ Scale-independence Fractal $\cdot$ Scaling

Resale or republication not permitted without written consent of the publisher

\section{INTRODUCTION}

In aquatic ecosystems, zooplankton organisms use a range of strategies to search for food, hosts and sexual partners and to avoid predators. Examples encompass a wide spectrum of swimming behaviors, with reported variability related to the species (Tiselius \& Jonsson 1990), the age (Coughlin et al. 1992, Van Duren \& Videler 1995, Paffenhöfer et al. 1996, Titelman 2001, Titelman \& Kiørboe 2003a), food quality and quantity (Tiselius 1992, Bundy et al. 1993, Paffenhöfer \& Mazzocchi 2002), the presence of a predator or a conspecific (Van Duren \& Videler 1996, Tiselius et al. 1997, Doall et al. 1998, Yen et al. 2004, Titelman \& Kiørboe 2003b) or the sex of individuals (Van Duren \& Videler 1995,
Brewer 1998, Strickler 1998). The information imparted into the surrounding water by a swimming animal (Yen \& Strickler 1996, Gries et al. 1999), including both chemical (Weissburg et al. 1998, Yen et al. 1998) and hydromechanical (Costello et al. 1990, Marrasé et al. 1990, Hwang \& Strickler 1994, 2001, Hwang et al. 1994, Van Duren et al. 1998, Seuront et al. 2004a) stimuli, has also been reported as a source of behavioral variability.

The movement patterns of zooplankton swimming behavior are also likely to be affected by environmental complexity such as resource patchiness (Tiselius 1992, Tiselius et al. 1993). Considering the increasing awareness of the heterogeneous nature of physical and biological patterns and processes at scales relevant to individual organisms (Cowles et al. 1998, Seuront et al. 
1996a,b, 1999, 2002, Seymour et al. 2000, 2004, Waters \& Mitchell 2002, Waters et al. 2003, Seuront \& Schmitt 2004), there is a genuine need to establish a reference framework that will link pure behavioral observations, the qualitative and quantitative nature of environment complexity and zooplankton trophodynamic hypotheses (Keiyu et al. 1994, Seuront et al. 2001, 2004b, Schmitt \& Seuront 2001, 2002). Key processes such as competition, mating and predation occur across distances of centimeters; however, the consequences of these interactions influence processes such as climate and fisheries productivity up to the global scale (Kolber et al. 2001, Rivkin \& Legendre 2001). In this context, and considering the extremely intertwined properties of swimming and feeding processes in copepod ecology (Jiang 2004), the testing of mechanistic hypotheses relating individual movements to higher-level ecological phenomena requires that individual swimming pathways be precisely characterized, both qualitatively and quantitatively.

This task may be more challenging than it appears at first glance. In addition to the widely acknowledged difficulty associated with collecting time series of 3dimensional high-spatial-resolution behavioral data, previous behavioral studies were subject to legitimate criticism related to the few replicates of individual animals examined and/or to the tethering techniques used to maintain the animal in focus. Turner et al. (1993) thus reported that in terms of time allocation to various behaviors, animal-to-animal variability of 5 tethered adult females of Calanus finmarchicus was significantly greater than any pattern related to food concentration. Hwang et al. (1993) found that for a group of 10 adult females of Centropages hamatus, variability for tethered animals was significantly greater than for freeswimming ones. As individual variability has also been highlighted in copepod feeding activity (Paffenhöfer 1994, Paffenhöfer et al. 1996), we stress the need to assess the behavioral ecology of copepods by investigating numerous free-swimming animals.

In addition, behavioral ecologists face another, more fundamental, problem (Seuront et al. 2004b). Most of the quantitative metrics commonly applied in behavioral studies, e.g. path length, turning rate and net-togross displacement ratio (NGDR), are indeed scale dependent. That is, the metrics will take on different values depending on the physical or temporal scale at which they are measured (Seuront et al. 2004b). This issue is even more critical considering that individual studies typically recorded behaviors at different temporal resolutions, i.e. ranging from 0.01 to $60 \mathrm{~Hz}$ (Table 1). The scale dependence inherent in most metrics results in there being no single scale at which swimming paths can be unambiguously described. Thus, there is no single scale at which swimming behaviors can be com- pared without leading to arbitrary and potentially spurious conclusions. Despite the limitations related to scale-dependent metrics, as far as we know, only a few studies have analyzed plankton swimming behavior in a scale-independent framework (Table 1).

Considering that only few zooplankton species (mainly calanoids in the marine environment, see Table 1) have been the subject of behavioral studies, the objective of this work is to extend behavioral studies to the seldom-studied sub-tropical copepod Oncaea venusta. O. venusta is a very common and widely distributed copepod species in the waters of Taiwan (Hwang \& Turner 1995, Shih \& Chiu 1998, Lo et al. 2001, 2004, 2004, Hsieh \& Chiu 2002, Wu et al. 2004), Japan (Ueda 1991) and Hong Kong (Chen et al. 2003, Lee \& Chen 2003). A preliminary study of swimming behavior of $O$. venusta females under a dissecting microscope was carried out by Hwang \& Turner (1995). In the past decade, a laser video optical system has been commonly used to observe the swimming trajectories and behavior of tiny marine organisms (Costello et al. 1990, Marrasé et al. 1990, Trager et al. 1990, Hwang et al. 1993, 1994, 1998, Hwang \& Strickler 1994, 2001, Strickler \& Hwang 1999, Shih \& Hwang 2000). We used a similar technique for this study. On the basis of an extended data set including 44 swimming paths we investigated: (1) the scale-independent properties of the swimming behavior of $O$. venusta and (2) the individual variability in the swimming behavior of free-swimming males. Standard scale-dependent metrics such as swimming speed and NGDR have been estimated as a reference framework and compared to the scale-independent analysis. Finally, the implications of the observed patterns are discussed in the general framework of the behavioral ecology of zooplankton.

\section{MATERIALS AND METHODS}

Experimental procedures and behavioral observations. Copepods were collected in surface, free-drifting net tows with standard Norpac zooplankton nets (45 cm mouth diameter, $180 \mathrm{~cm}$ in length and $333 \mu \mathrm{m}$ mesh) from offshore waters near the National Taiwan Ocean University, Keelung, on the northeast coast of Taiwan. All sampling was conducted by 'Ocean Research Vessel II' in the daytime from 18 to 22 July 1997. There were several cruises per day to collect actively swimming copepods. Samples were returned to the laboratory within $<1 \mathrm{~h}$ of each cruise, and actively swimming adult copepods of Oncaea venusta were sorted into rectangular experimental vessels of 5 $\times 10 \times 10 \mathrm{~cm}$ containing $400 \mathrm{ml}$ of $63 \mu \mathrm{m}$ screened natural seawater from the site of collection. To avoid confounding the swimming behavior of males and 
Table 1. Literature survey of zooplankton behavioral studies, arranged in chronological order from 1964 to 2004 (1NGDR: net-to-gross displacement rate; 2MFDR: length of male pursuit trajectory/length of female trajectory; 3RMSD: root-mean-sqaure displacement)

\begin{tabular}{|c|c|c|c|c|}
\hline Organism & View & Variable & Metrics [temporal scale] & Authors \\
\hline Daphnia ${ }^{\mathrm{b}}$ & $2 \mathrm{D}$, side & Relative light intensity & Speed, position in the water column [-] & Ringelberg (1964) \\
\hline Cyclops $^{\mathrm{b}}$ & $2 \mathrm{D}$, side & Light & Speed $[0.1 \mathrm{~Hz}]$ & Strickler (1970) \\
\hline Daphnia & $2 \mathrm{D}$, top & Polarized light & Speed, NGDR, IDT, turning rate [30 Hz] & Wilson \& Greaves (1979) \\
\hline Mesocyclops $^{\mathrm{b}}$ & $2 \mathrm{D}$, top & Prey patches & Speed, loops/min $[0.01 \mathrm{~Hz}]$ & Williamson (1981) \\
\hline Daphnia ${ }^{\mathrm{b}}$ & $3 \mathrm{D}$ & Angular light distribution & Speed, NGDR1 [-] & Buchanan et al. (1982) \\
\hline Daphnia ${ }^{\mathrm{b}}$ & 2D, side & Food concentration & Speed $[0.1 \mathrm{~Hz}]$ & Porter et al. (1982) \\
\hline Acartia & $2 \mathrm{D}$, top & $\begin{array}{l}\text { Bioluminescent } \\
\text { dinoflagellates }\end{array}$ & Speed, NGDR1, bursts [15 Hz] & Buskey et al. (1983) \\
\hline Pseudocalanus & $2 \mathrm{D}$, top & $\begin{array}{l}\text { Food concentration and } \\
\text { odors }\end{array}$ & Speed, NGDR1, bursts, pauses [15 Hz] & Buskey (1984) \\
\hline Diaptomus & $2 \mathrm{D}$, top & Predators \& competitors & Speed, NGDR1, time between jumps [30 Hz] & Wong et al. (1986) \\
\hline Daphnia ${ }^{\mathrm{b}}$ & $3 \mathrm{D}$ & Food concentration & Speed, turning rate, ground covered [30 Hz] & Young \& Getty (1987) \\
\hline Euchaeta & $3 \mathrm{D}$ & $\begin{array}{l}\text { Predator-prey/male- } \\
\text { female interactions }\end{array}$ & Speed, turning rate & Yen (1988) \\
\hline Favella & 2D, side & Food patches & Speed, NGDR1, turning rate [15 Hz] & Buskey \& Stoecker (1988) \\
\hline Thysanoessa & $3 \mathrm{D}$ & Algal patches & Speed, NGDR1, bursts, \% sinking [2 Hz] & Price (1989) \\
\hline Six calanoids & 2D, side & Light, food type & Speed, foraging mode $[12.5 \mathrm{~Hz}]$ & Tiselius \& Jonsson (1990) \\
\hline Polyphemu & $2 \mathrm{D}$, top & Predator-prey interaction & Speed, turning rate, meander $[1 \mathrm{~Hz}]$ & Young \& Taylor (1990) \\
\hline Bosmina & $2 \mathrm{D}$, top & Predator-prey interaction & Speed, turning rate, meander $[1 \mathrm{~Hz}]$ & Young \& Taylor (1990) \\
\hline Daphnia & $3 \mathrm{D}$ & Body size & $\begin{array}{l}\text { Speed, displacement angle, NGDR, } \\
\text { stroke velocity, sinking speed [30 Hz] }\end{array}$ & Dodson \& Ramcharan (1991) \\
\hline Diaptomus & $3 \mathrm{D}$ & Predators & Speed, jump length, angle of motion $[20 \mathrm{~Hz}]$ & Ramcharan \& Sprules (1991) \\
\hline Diaptomus & $2 \mathrm{D}$, top & Conspecifics & Speed, NGDR1 [-] & Van Leeuwen \& Maly (1991) \\
\hline Acartia & $2 \mathrm{D}$, side & Turbulence & Speed, foraging activity and behavior [25 Hz] & Saiz \& Alcaraz (1992) \\
\hline Amphiprion $^{\mathrm{a}}$ & $3 \mathrm{D}$ & Food concentration & $\begin{array}{l}\text { Speed, NGDR1, turning angles, } \\
\text { fractal dimension [10-15 Hz] }\end{array}$ & Coughlin et al. (1992) \\
\hline Acartia & 2D, side & Food patches & $\begin{array}{l}\text { Speed, vertical position, jump frequency, } \\
\text { NGDR [0.1 Hz] }\end{array}$ & Tiselius (1992) \\
\hline Centropages & $3 \mathrm{D}$ & Food concentration & $\begin{array}{l}\text { Speed, NGDR1, Realized Encounter } \\
\text { Volume, i.e. fractal dimension }[30 \mathrm{~Hz}]\end{array}$ & Bundy et al. (1993) \\
\hline Various species & $2 \mathrm{D}$, side & Species & $\begin{array}{l}\text { Speed, NGDR1, rate of change } \\
\text { in direction }[15-30 \mathrm{~Hz}]\end{array}$ & Buskey et al. (1993) \\
\hline Diaptomus & $2 \mathrm{D}$, top & Gravid females & Speed, NGDR1 [-] & Maly et al. (1994) \\
\hline Acartia & $3 \mathrm{D}$ & Food, turbulence & Speed, behavioral observations [30 Hz] & Saiz (1994) \\
\hline Oithona & $2 \mathrm{D}$, top & Behavior & $\begin{array}{l}\text { Duration of swimming/non-swimming } \\
\text { behaviors, behavioral transitions frequency [3 Hz] }\end{array}$ & Hwang \& Turner (1995) \\
\hline Temora & $2 \mathrm{D}$, top & Behavior & $\begin{array}{l}\text { Duration of swimming/non-swimming } \\
\text { behaviors, behavioral transitions frequency [3 Hz] }\end{array}$ & Hwang \& Turner (1995) \\
\hline Macrosetella & $2 \mathrm{D}$, top & Behavior & $\begin{array}{l}\text { Duration of swimming/non-swimming } \\
\text { behaviors, behavioral transitions frequency [3 Hz] }\end{array}$ & Hwang \& Turner (1995) \\
\hline Undinula & $2 \mathrm{D}$, top & Behavior & $\begin{array}{l}\text { Duration of swimming/non-swimming } \\
\text { behaviors, behavioral transitions frequency [3 Hz] }\end{array}$ & Hwang \& Turner (1995) \\
\hline Oncaea & $2 \mathrm{D}$, top & Behavior & $\begin{array}{l}\text { Duration of swimming/non-swimming } \\
\text { behaviors, behavioral transitions frequency [3 Hz] }\end{array}$ & Hwang \& Turner (1995) \\
\hline Brachionus & $2 \mathrm{D}$, top & Toxic stress & Speed, sinuosity, behavioral observations [25 Hz] & Charoy et al. (1995) \\
\hline Temora & $3 \mathrm{D}$ & Food concentration & Speed, NGDR1, behavioral observations [50 Hz] & Van Duren \& Videler (1995) \\
\hline Dioithona & $2 \mathrm{D}$, side & Light, water flow & Speed, rate of change in directions $[30 \mathrm{~Hz}]$ & Buskey et al. (1996) \\
\hline Oithona & $2 \mathrm{D}$ & Developmental stage & Speed, behavioral observations [30 Hz] & Paffenhöfer et al. (1996) \\
\hline Temora & $2 \mathrm{D}, 3 \mathrm{D}$ & Predators, conspecifics & Speed, NGDR1, behavioral observations [50 Hz] & Van Duren \& Videler (1996) \\
\hline Daphnia ${ }^{\mathrm{b}}$ & $3 \mathrm{D}$ & $\begin{array}{l}\text { Food concentration, light, } \\
\text { temperature }\end{array}$ & $\begin{array}{l}\text { Speed, turning angle, turning rate, } \\
\text { NGDR, fractal dimension }[10 \mathrm{~Hz}]\end{array}$ & Brewer (1996) \\
\hline Daphnia ${ }^{\mathrm{b}}$ & $2 \mathrm{D}$, top & Food concentration & Speed $[-]$ & Larsson \& Kleiven (1996) \\
\hline Daphnia ${ }^{b}$ & $3 \mathrm{D}$ & $\begin{array}{l}\text { Light, food concentration, } \\
\text { vessel size }\end{array}$ & Speed, turning angle [30 Hz] & Dodson et al. (1997) \\
\hline Acartia & $2 \mathrm{D}$ & Predators & Encounter rates [-] & Tiselius et al. (1997) \\
\hline Euplotes & $2 \mathrm{D}$, top & Food patches & Speed, motility, fractal dimension $[-]$ & Jonsson \& Johansson (1997) \\
\hline Protoperidinium & $2 \mathrm{D}$, top & Food type & $\begin{array}{l}\text { Speed, rate of change of direction, } \\
\text { behavioral observations [15 Hz] }\end{array}$ & Buskey (1997) \\
\hline Centropages & $2 \mathrm{D}$ & $\begin{array}{l}\text { Turbulence, food } \\
\text { concentration }\end{array}$ & $\%$ Swimming, swimming behavior, jumps [25 Hz] & Caparroy et al. (1998) \\
\hline
\end{tabular}


Table 1. (continued)

\begin{tabular}{|c|c|c|c|c|}
\hline Organism & View & Variable & Metrics [temporal scale] & Authors \\
\hline Cyclops $^{\mathrm{b}}$ & $3 \mathrm{D}$ & Conspecifics & Speed, distance between male and female [60 Hz] & Strickler (1998) \\
\hline Daphnia ${ }^{\mathrm{b}}$ & $3 \mathrm{D}$ & Predators & $\begin{array}{l}\text { Speed, turning angle, behavioral observations } \\
{[30 \mathrm{~Hz}]}\end{array}$ & O'Keefe et al. (1998) \\
\hline Temora & $3 \mathrm{D}$ & Sex, mating & Speed, NGDR1, encounter, MFDR2 [60 Hz] & Doall et al. (1998) \\
\hline Temora & $3 \mathrm{D}$ & Sex, mating & Speed, turning angle, NGDR1 [60 Hz] & Weissburg et al. (1998) \\
\hline Calanus & $2 \mathrm{D}$ & Sex, mating & Speed, behavioral observations [0.27-4.55 Hz] & Tsuda \& Miller (1998) \\
\hline Temora & $3 \mathrm{D}$ & Sex, mating & Speed, RMSD3, diffusion & Yen et al. (1998) \\
\hline Daphnia & $3 \mathrm{D}$ & Sex, mating & $\begin{array}{l}\text { Speed, turning angle, distance between } \\
\text { male and female }[25 \mathrm{~Hz}]\end{array}$ & Brewer (1998) \\
\hline Lates calcarifer ${ }^{\mathrm{a}}$ & $2 \mathrm{D}$, top & Food concentration & $\begin{array}{l}\text { Pause duration, distance travelled between } \\
\text { pauses, travel duration, developmental stage, } \\
\text { fractal dimension [ } 25 \mathrm{~Hz}]\end{array}$ & Dowling et al. (2000) \\
\hline Pomacentrus ${ }^{\mathrm{a}}$ & 1D, side & Age & Speed $[-]$ & Fisher et al. (2000) \\
\hline Sphaeramia ${ }^{\mathrm{a}}$ & 1D, side & Age & Speed $[-]$ & Fisher et al. (2000) \\
\hline Amphiprion $^{\mathrm{a}}$ & 1D, side & Age & Speed $[-]$ & Fisher et al. (2000) \\
\hline Acartia & $2 \mathrm{D}$, side & Predators & Speed, reaction distance, jumps [60 Hz] & Suchman (2000) \\
\hline Acartia & $3 \mathrm{D}$ & Age, predators & $\begin{array}{l}\text { Speed, jump directionality, frequency, } \\
\text { length and speed [-] }\end{array}$ & Titelman (2001) \\
\hline Temora & $3 \mathrm{D}$ & Age, predators & $\begin{array}{l}\text { Speed, jump directionality, frequency, } \\
\text { length and speed [-] }\end{array}$ & Titelman (2001) \\
\hline Temora & $3 \mathrm{D}$ & Behavior & Multifractal parameters $[12.5 \mathrm{~Hz}]$ & $\begin{array}{l}\text { Schmitt \& Seuront }(2001, \\
\text { 2002) }\end{array}$ \\
\hline Oithona & $3 \mathrm{D}$ & $\begin{array}{l}\text { Food quality and } \\
\text { quantity }\end{array}$ & $\begin{array}{l}\text { Sinking speed and modality, frequency, } \\
\text { speed and direction of jumping [60 Hz] }\end{array}$ & $\begin{array}{l}\text { Paffenhöfer \& Mazzocchi } \\
(2002)\end{array}$ \\
\hline Clupea harengus ${ }^{\mathrm{a}}$ & $2 \mathrm{D}$ & Age, turbulence, light & $\begin{array}{l}\text { Attack rate and swimming activity (duration } \\
\text { of time swimming and duration of swimming } \\
\text { bout) }[-]\end{array}$ & Utne-Palm \& Stiansen (2002) \\
\hline Euchaeta & $3 \mathrm{D}$ & Prey & Speed, attack volume and angle [60 Hz] & Doall et al. (2003) \\
\hline Oxyrrhus marina & $2 \mathrm{D}$ & Food quantity & Lévy distribution, i.e. fractal dimension [12 Hz] & Bartumeus et al. (2003) \\
\hline Goldfish $^{\mathrm{a}}$ & $2 \mathrm{D}$ & Behavior & Lévy distribution, i.e. fractal dimension [30 Hz] & Faure et al. (2003) \\
\hline Acartia & $3 \mathrm{D}$ & Age & $\begin{array}{l}\text { Sinking, swimming and jumping speed, } \\
\text { behavioral observations [ } 25 \mathrm{~Hz}]\end{array}$ & Titelman \& Kiørboe (2003a) \\
\hline Calanus & $3 \mathrm{D}$ & Age & $\begin{array}{l}\text { Sinking, swimming and jumping speed, } \\
\text { behavioral observations [ } 25 \mathrm{~Hz}]\end{array}$ & Titelman \& Kiørboe (2003a) \\
\hline Centropages & $3 \mathrm{D}$ & Age & $\begin{array}{l}\text { Sinking, swimming and jumping speed, } \\
\text { behavioral observations }[25 \mathrm{~Hz}]\end{array}$ & Titelman \& Kiørboe (2003a) \\
\hline Euterpina & $3 \mathrm{D}$ & Age & $\begin{array}{l}\text { Sinking, swimming and jumping speed, } \\
\text { behavioral observations [ } 25 \mathrm{~Hz}]\end{array}$ & Titelman \& Kiørboe (2003a) \\
\hline Temora & $3 \mathrm{D}$ & Age & $\begin{array}{l}\text { Sinking, swimming and jumping speed, } \\
\text { behavioral observations [ } 25 \mathrm{~Hz}]\end{array}$ & Titelman \& Kiørboe (2003a) \\
\hline Acartia & $3 \mathrm{D}$ & Age, predators & $\begin{array}{l}\text { Sinking and swimming speed, escape jump length, } \\
\text { speed and direction [25 Hz] }\end{array}$ & Titelman \& Kiørboe (2003b) \\
\hline Calanus & $3 \mathrm{D}$ & Age, predators & $\begin{array}{l}\text { Sinking and swimming speed, escape jump length, } \\
\text { speed and direction [25 Hz] }\end{array}$ & Titelman \& Kiørboe (2003b) \\
\hline Centropages & $3 \mathrm{D}$ & Age, predators & $\begin{array}{l}\text { Sinking and swimming speed, escape jump length, } \\
\text { speed and direction }[25 \mathrm{~Hz}]\end{array}$ & Titelman \& Kiørboe (2003b) \\
\hline Euterpina & $3 \mathrm{D}$ & Age, predators & $\begin{array}{l}\text { Sinking and swimming speed, escape jump length, } \\
\text { speed and direction [25 Hz] }\end{array}$ & Titelman \& Kiørboe (2003b) \\
\hline Temora & $3 \mathrm{D}$ & Age, predators & $\begin{array}{l}\text { Sinking and swimming speed, escape jump length, } \\
\text { speed and direction [25 Hz] }\end{array}$ & Titelman \& Kiørboe (2003b) \\
\hline Daphnia & 2D, side & Turbulence, light & Speed, direction of motion, fractal dimension [30 Hz] & Seuront et al. (2004a) \\
\hline Temora & 2D, side & Turbulence, light & Speed, direction of motion $[30 \mathrm{~Hz}]$ & Seuront et al. (2004a) \\
\hline Daphnia $^{\mathrm{b}}$ & $3 \mathrm{D}$ & Behavior & Path length, turning angle, fractal dimension $[12.5 \mathrm{~Hz}]$ & Seuront et al. (2004b) \\
\hline Daphnia ${ }^{b}$ & $3 \mathrm{D}$ & Behavior & Multifractal parameters [12.5 Hz] & Seuront et al. (2004c) \\
\hline Temora & $3 \mathrm{D}$ & Behavior & Multifractal parameters $[12.5 \mathrm{~Hz}]$ & Seuront et al. (2004c) \\
\hline
\end{tabular}


females due to the presence of the opposite sex, separate experiments were conducted on males (size range: 0.90 to $1.00 \mathrm{~mm}$ ) and females (0.80 to $1.16 \mathrm{~mm})$. The similar laser video optical systems of Hwang et al. (1994), Hwang \& Strickler (1994, 2001), Strickler \& Hwang (1999) were used in this study to examine the swimming behavior of $O$. venusta. The experiment was done by filming actively free-swimming $O$. venusta, using a laser light source with a video camera, a videocassette recorder, a frame counter and a monitor.

Quantifying zooplankton swimming behavior. Movement paths may be characterized by a variety of measures (Table 1), including path length (the total distance traveled, or gross displacement), move length (the distance traveled between consecutive points in time), move duration (the time interval between successive pauses, as well as between successive spatial points), speed (the move length divided by move duration), turning angle (the difference in direction between 2 successive moves), turning rate (the turning angle divided by move duration), net displacement (the linear distance between starting and ending point, i.e. NGDR), and fractal dimension. For paths recorded at fixed time intervals, move duration is a constant. As extensively discussed in Seuront et al. (2004b), the values of all the metrics are implicitly a function of their measurement scale (Fig. 1). The scale dependence of standard metrics implies that there is no single scale at which swimming paths can be unambiguously described. This is not the case, however, for fractal dimensions, which are independent of scale and therefore have the potential to become a reference framework in analyzing and inferring behavioral data. Because fractal dimensions have seldom been applied to zooplankton behavior (Table 1), we also used 2 of the most common behavioral measures, swimming speed and NGDR, as a reference framework to allow the reader to make comparisons with previous studies having similar temporal resolution.

Swimming speed and NGDR: The distance $d$ $(\mathrm{mm})$ traveled between 2 successive video frames was computed from the $(x, y)$ coordinates as:

$$
d=\left[\left(x_{t}-x_{t+1}\right)^{2}+\left(y_{t}-y_{t+1}\right)^{2}\right]^{1 / 2}
$$

where $\left(x_{t}, y_{t}\right)$ and $\left(x_{t+1}, y_{t+1}\right)$ are the positions of a copepod at time $t$ and $t+1$, respectively. The swimming speed $v\left(\mathrm{~mm} \mathrm{~s}^{-1}\right)$ was subsequently estimated as:

$$
V=d f
$$

where $f$ is the sampling rate of the camera, i.e. $f=$ 30 frame s$^{-1}$. Average swimming speeds and their standard deviations were measured over the duration of each individual track.

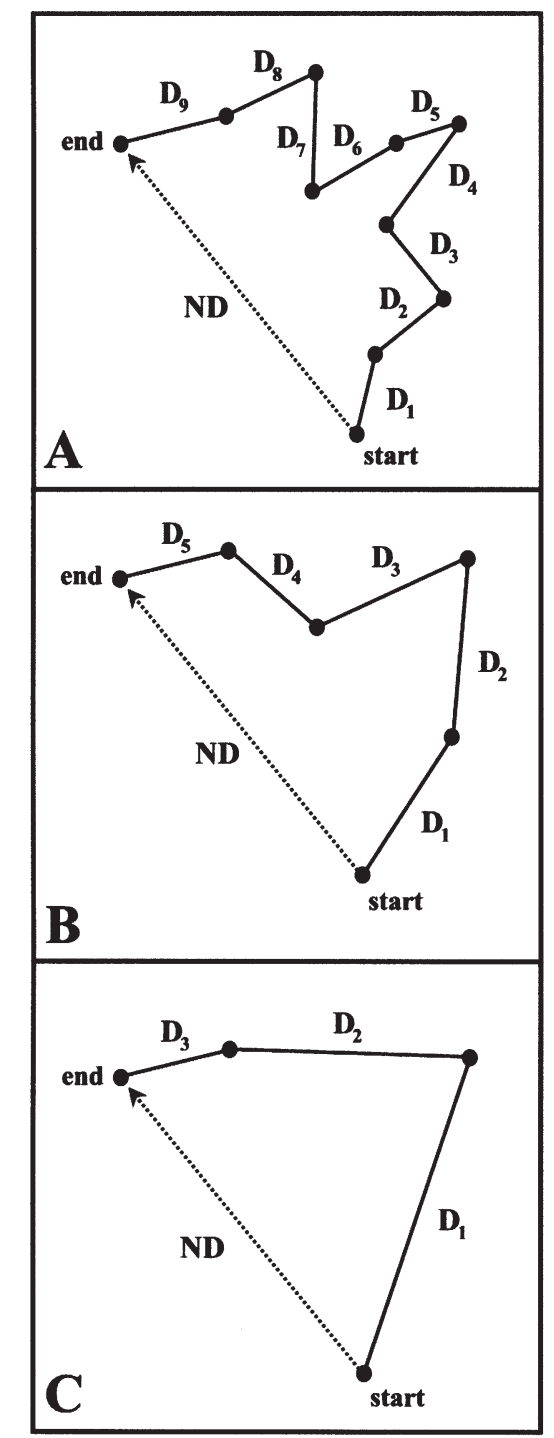

Fig. 1. Illustration of the concept of scale dependence in the net-to-gross displacement rate (NGDR) shown at 3 different resolutions. The net displacement (ND) is the straight-line distance between the initial and final locations, and the growth displacement is the sum of the distances $D_{i}$

NGDRs were computed according to Buskey (1984):

$$
\mathrm{NGDR}=\mathrm{ND} / \mathrm{GD}
$$

where ND (mm) and GD (mm) are the net and gross displacements of a copepod, which correspond to the shortest distance between the starting and ending points of the trajectory and the actual distance traveled by the copepod, respectively. The NGDR provides a measure of the relative linearity of copepod swimming paths, with lower NGDRs implying more curved trajectories than higher NGDRs. NGDRs were computed at the smallest available resolution (i.e. $1 / 30 \mathrm{~s}$ ) for each individual track. 
Fractal dimension: The above-stated traditional metrics used to characterize animal movements are scale dependent; see Seuront et al. (2004b) for further discussion. We thus used fractal analysis, which is based on the premise that the fractal dimension can serve as a scale-independent descriptor of the path an organism takes as it swims about. If an organism moves along a completely linear path, then the actual distance traveled, $L$, equals the displacement between the start and the finish, 1. The relationship between these 2 variables is linear. In other words, if we assume a power law relating $L$ to 1 , i.e. $L^{D}=1$, then the exponent $D=1$. According to this power law, if the path deviates from linearity, that is, becomes curvy, the exponent will then be $>1$. In the extreme example of curviness, i.e. for the case of Brownian motion in 2 dimensions, $D=2$ (Mandelbrot 1983). It appears that $D$ provides a measure of the path 'complexity', with the extreme cases delineated by linear and Brownian movement, respectively. Real-life cases are expected to fall between these extremes.

Formally, the fractal dimension $D$ is estimated by superimposing a regular grid of pixels of length $\lambda$ on the object and counting the number of 'occupied' pixels (Fig. 2). This procedure is repeated using different values for $\lambda$. The volume occupied by a path is then estimated with a series of counting boxes, spanning a range of volumes down to some small fraction of the entire volume (Fig. 2). The number of occupied boxes increases with decreasing box size, leading to the following power-law relationship:

$$
N(\lambda)=\mathrm{k}_{1} \lambda^{-D}
$$

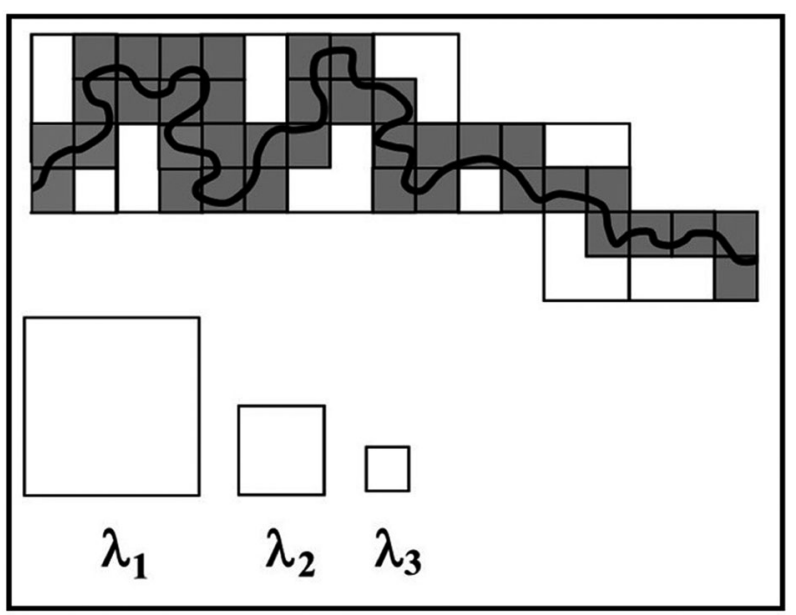

Fig. 2. Two-dimensional illustration of the box-counting method used to describe swimming path complexity with fractal dimension. Three steps of the analyses are shown, using 3 different characteristic box sizes $\lambda_{1}, \lambda_{2}$ and $\lambda_{3}$ where $\lambda$ is the box size, $N(\lambda)$ is the number of boxes occupied by the path, $\mathrm{k}$ is a constant and $D$ is the boxcounting fractal dimension, also referred to as the box dimension. $D$ is estimated from the slope of the linear trend of the $\log -\log$ plot of $N(\lambda)$ versus $\lambda$. Because slight reorientation of the overlying grid can produce different values of $N(\lambda)$ (Appleby 1996), the fractal dimension $D$ has been estimated for rotation of the initial $2 \mathrm{D}$ grid of $5^{\circ}$ increments from 0 to $45^{\circ}$.

Because an objective procedure is needed to decide upon an appropriate range of scales to include in the regressions, we used the values of the time scales, which satisfied a statistically sound criterion. We consider a regression window of varying width ranging from a minimum of 5 data points (the least number of data points to ensure the statistical relevance of a regression analysis) to the entire data set. The smallest windows are slid along the entire data set at the smallest available increments, with the whole procedure iterated $n-4$ times, where $n$ is the total number of available data points. Within each window and for each width, we estimated the coefficient of determination $\left(\mathrm{r}^{2}\right)$ and the sum of the squared residuals for the regression. We subsequently used the values of $\lambda$ (Eq. 4), which maximized the coefficient of determination and minimized the total sum of the squared residuals (Seuront \& Lagadeuc 1997, Seuront et al. 2004b,c), to define the scaling range and to estimate the related dimensions $D$.

Statistical analyses. As the distribution of the estimated parameters (swimming speed, NGDR and fractal dimension) were non-normally distributed (Kolmogorov-Smirnov test, $\mathrm{p}<0.01$ ), non-parametric statistics were used throughout this work. Malefemale comparisons were carried out using the Wilcoxon Mann-Whitney $U$-test (WMW test hereafter). Multiple comparisons between males and females were conducted using the Kruskal-Wallis test (KW test hereafter), and the Jonckheere test for ordered alternatives (Siegel \& Castellan 1988) was used to identify distinct groups of fractal dimensions.

The intra-individual and inter-individual variability was expressed as the coefficient of variation $\mathrm{CV}(\mathrm{CV}=$ $\mathrm{SD} / \bar{X}$ ) of swimming speeds and fractal dimensions estimated within and between all individual paths. Because 1 NGDR value was obtained for each individual path, only the inter-individual variability in NGRDs was considered.

Correlation between variables was investigated using Kendall's coefficient of rank correlation, $\tau$ (Kendall \& Stuart 1966). Kendall's coefficient was used in preference to Spearman's coefficient of correlation $\rho-$ although recommended in Kendall (1976) — because Spearman's $\rho$ gives greater weight to pairs of ranks that are further apart, while Kendall's $\tau$ weights each 

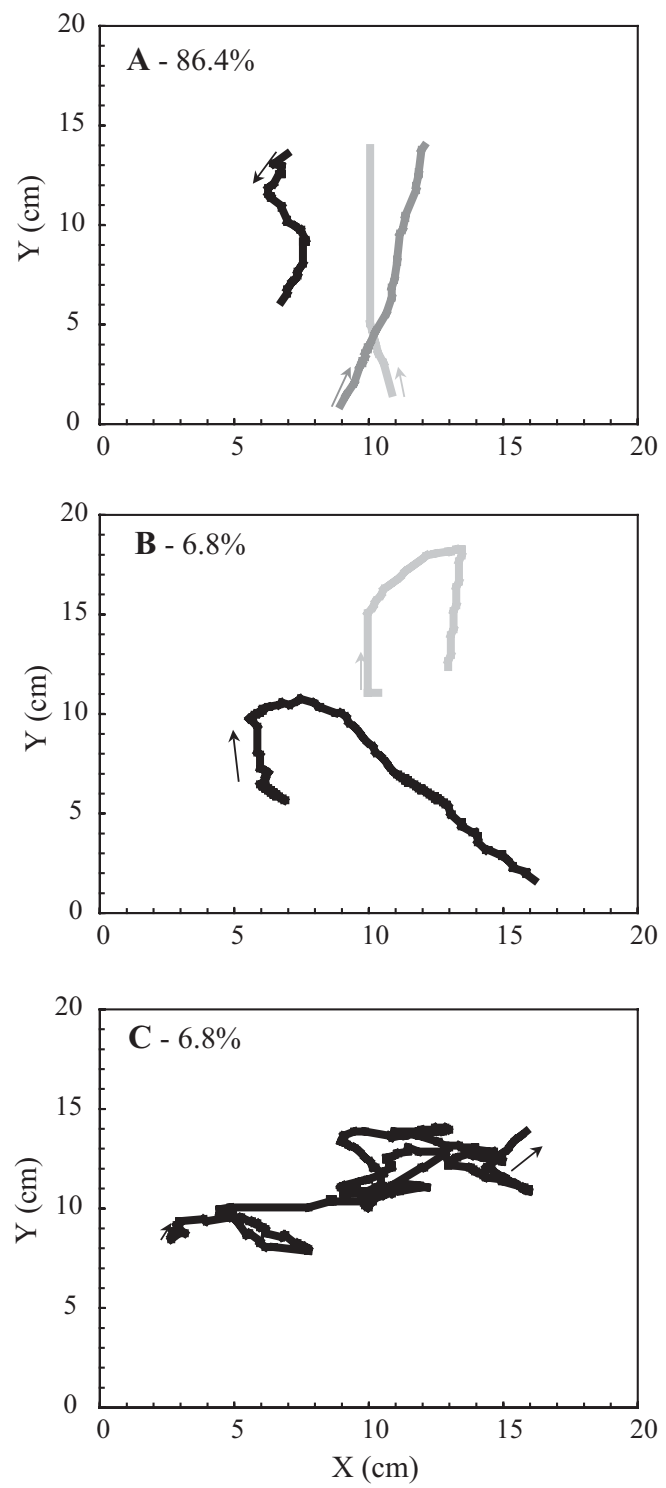

Fig. 3. Oncaea venusta. The 3 types of swimming behavior observed for males and referred to as rectilinear (A), 'Ashaped' (B) and tortuous (C)

disagreement in rank equally; see Sokal \& Rohlf (1995) for further discussion.

\section{RESULTS}

\section{Swimming paths}

Four types of swimming paths were visually identified for males and females of Oncaea venusta: rectilinear, 'A-shaped', 'V-shaped' and convoluted (Figs. 3 \& 4). A rectilinear swimming path (Figs. 3A, 4A) was the dominant swimming behavior observed for males $(86.4 \%)$ and females $(76.7 \%)$. These paths were traveled mainly in a vertical direction, for both males and females. 'A-shaped' and 'V-shaped' swimming paths were observed specifically for males (6.8\%) and females $(13.7 \%)$. Male 'A-shaped' paths were always traveled upward and downward (Fig. 3B), while female 'V-shaped' paths were traveled downward and upward (Fig. 4B). Finally, males and females showed tortuous swimming paths $(6.8 \%$ of males and $9.6 \%$ of females) that were restricted to the vertical direction for females (Fig. 4C) and more isotropic for males (Fig. 3C).
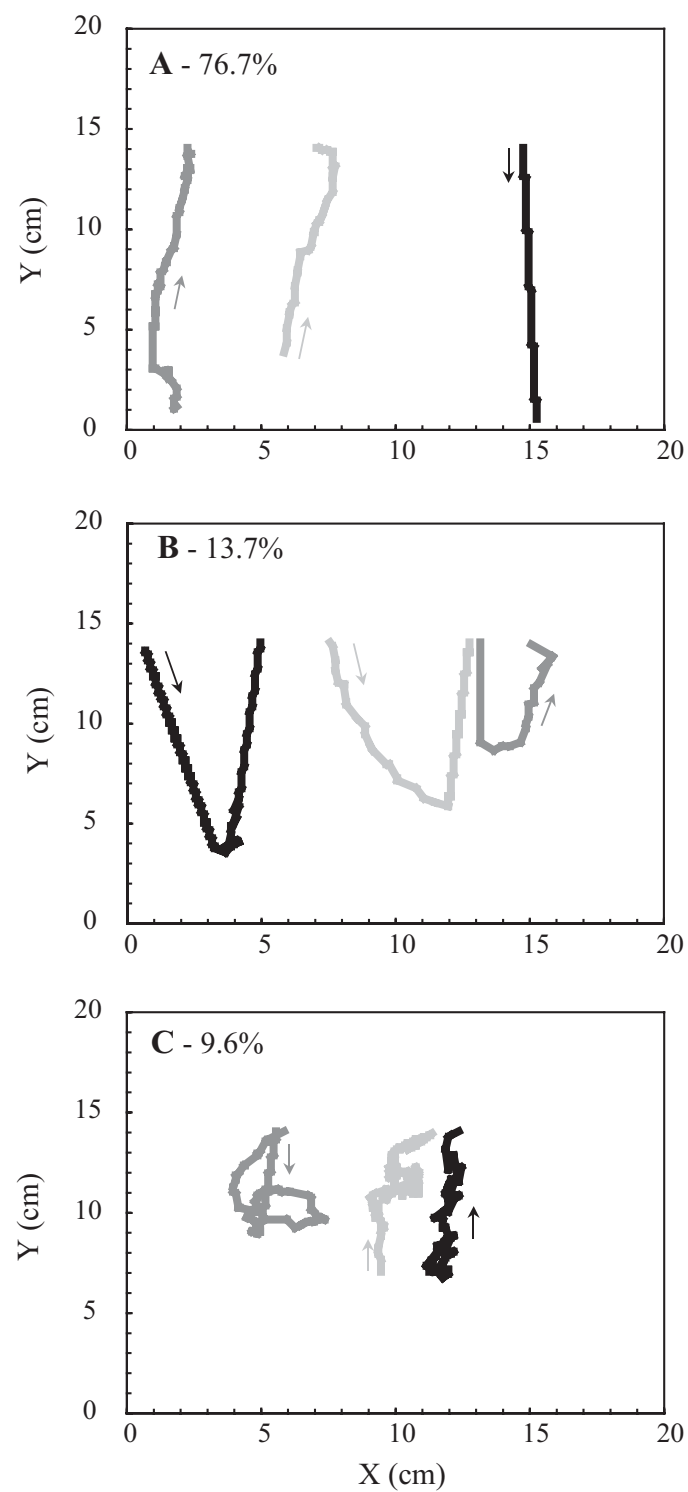

Fig. 4. Oncaea venusta. The 3 different types of swimming behaviors observed for females, and referred to as rectilinear (A), 'V-shaped' (B) and tortuous (C) 

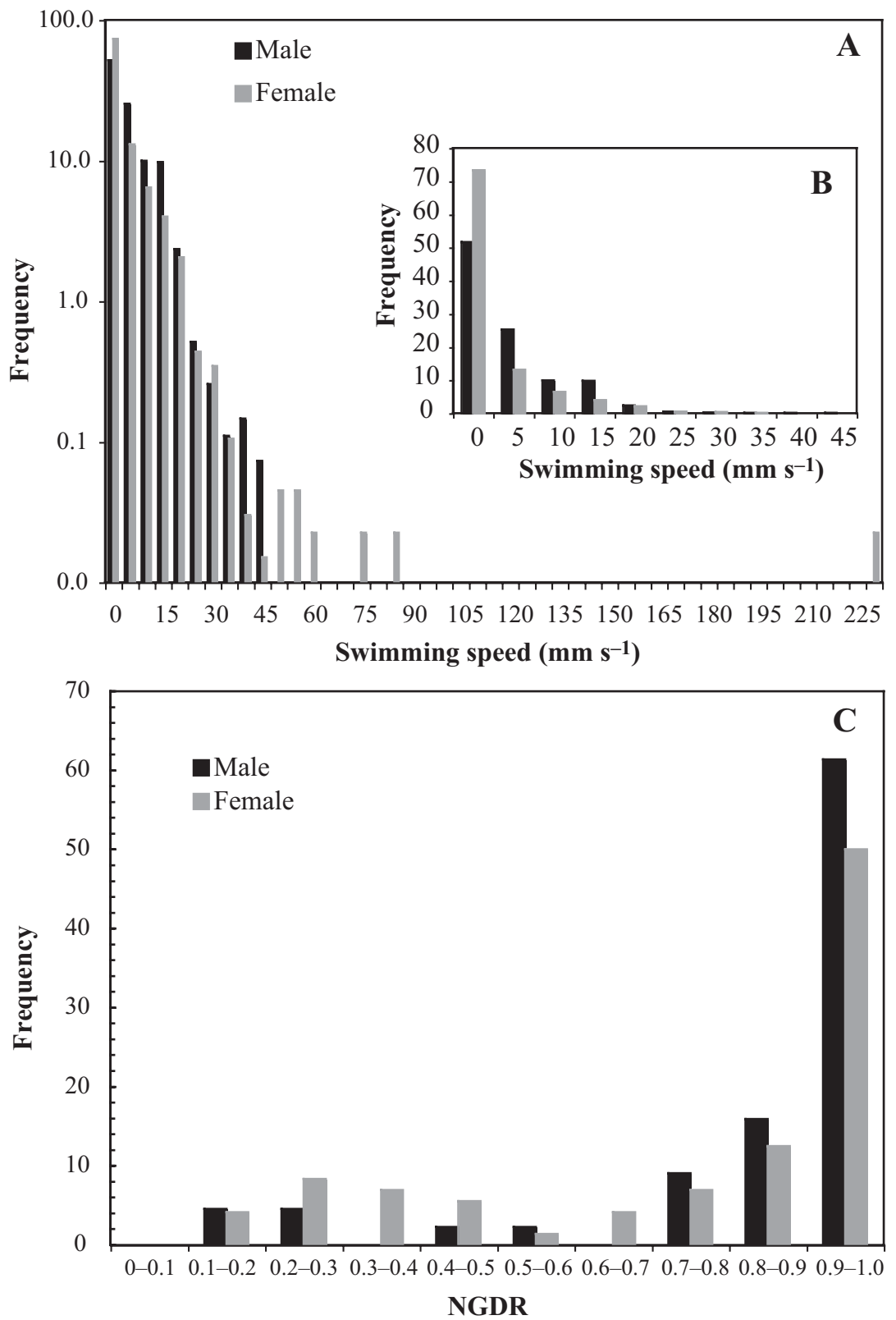

Fig. 5. Oncaea venusta. Swimming behavior of males $(\mathrm{n}=44)$ and females $(\mathrm{n}=73)$. (A) Frequency distribution of individual swimming speed measurements $(\mathrm{n}=2728$ for males and $\mathrm{n}=6641$ for females; logarithmic $y$-axis coordinates for speed ranging from 0 to $235 \mathrm{~mm} \mathrm{~s}^{-1}$ ). (B) Frequency distribution of individual swimming speed measurements for speed ranging from 0 to $50 \mathrm{~mm}$ $\mathrm{s}^{-1}$. (C) Frequency distribution of net-to-gross displacement ratios (NGDR) computed from 2728 and 6641 individual spatial positions for males and females, respectively

\section{Swimming speed and NGDR}

The swimming speeds of males and females of Oncaea venusta ranged from 0 to $46.6 \mathrm{~mm} \mathrm{~s}^{-1}$ and 0 to $231.3 \mathrm{~mm} \mathrm{~s}^{-1}$, respectively. While the frequency distribution of females is significantly more skewed than that of males (Figs. 5A, 6A \& B), males and females traveled at statistically similar speeds (WMW test, $\mathrm{p}>0.05$ ), averaging, respectively, $9.44 \pm 4.86 \mathrm{~mm}$ $\mathrm{s}^{-1}$ and $7.99 \pm 5.41 \mathrm{~mm} \mathrm{~s}^{-1}(\bar{x} \pm \mathrm{SD})$. However, significant differences $\left(\chi^{2}\right.$ test, $\mathrm{p}<0.01$ ) were found between the frequency of individual swimming speed measurements bounded between 0 and $5 \mathrm{~mm} \mathrm{~s}^{-1}$ and between 5 and $20 \mathrm{~mm} \mathrm{~s}^{-1}$. A significantly higher proportion of swimming speed $<5 \mathrm{~mm}$ $\mathrm{s}^{-1}$ was observed for females (Figs. 5A \& B, 6A), while a higher proportion of swimming speed bounded between 5 and $20 \mathrm{~mm} \mathrm{~s}^{-1}$ was found for males (Figs. 5A \& B, 6B).

The NGDRs of males ranged from 0.11 to 1.00 , averaging $0.84 \pm 0.24(\bar{X} \pm$ SD; Figs. 5C, 6C). The NGDRs of females were not significantly different (Figs. 5C, 6D; WMW test, p > 0.05), ranging from 0.14 to 1.00 and averag-

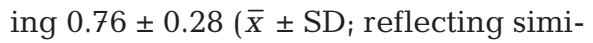
lar curves and loops in male and female swimming trajectories. A significantly higher proportion of NGDRs were nevertheless found in the range from 0.9 to 1.0 (Fig. 5C, $\chi^{2}$ test, $\mathrm{p}<0.01$ ), suggesting that the swimming behavior of males and females of Oncaea venusta was essentially rectilinear.

The observation of swimming speed and NGDR as the function of individual paths (Fig. 6) showed a predominance of individual variability. The intra-individual variability of swimming speed thus ranged from 0.06 to 1.41 for males and from 0.01 to 2.14 for females. The intra-individual variability is significantly higher for females than for males (WMW test, $\mathrm{p}>0.05$ ). The inter-individual variability of swimming speed is also higher for females $(\mathrm{CV}=0.64)$ than for males $(\mathrm{CV}=0.39)$, as the NGDR interindividual variability was $\mathrm{CV}=0.28$ for males and $\mathrm{CV}=0.39$ for females. Finally, no correlations were found between the 4 types of swimming paths and swimming speeds described above. NGDRs were consistently higher for tortuous and 'A-shaped' swimming paths for males (Fig. 6C), while for females low NGDRs (Fig. 6D) also included some rectilinear swimming paths (see Fig. 3A). 

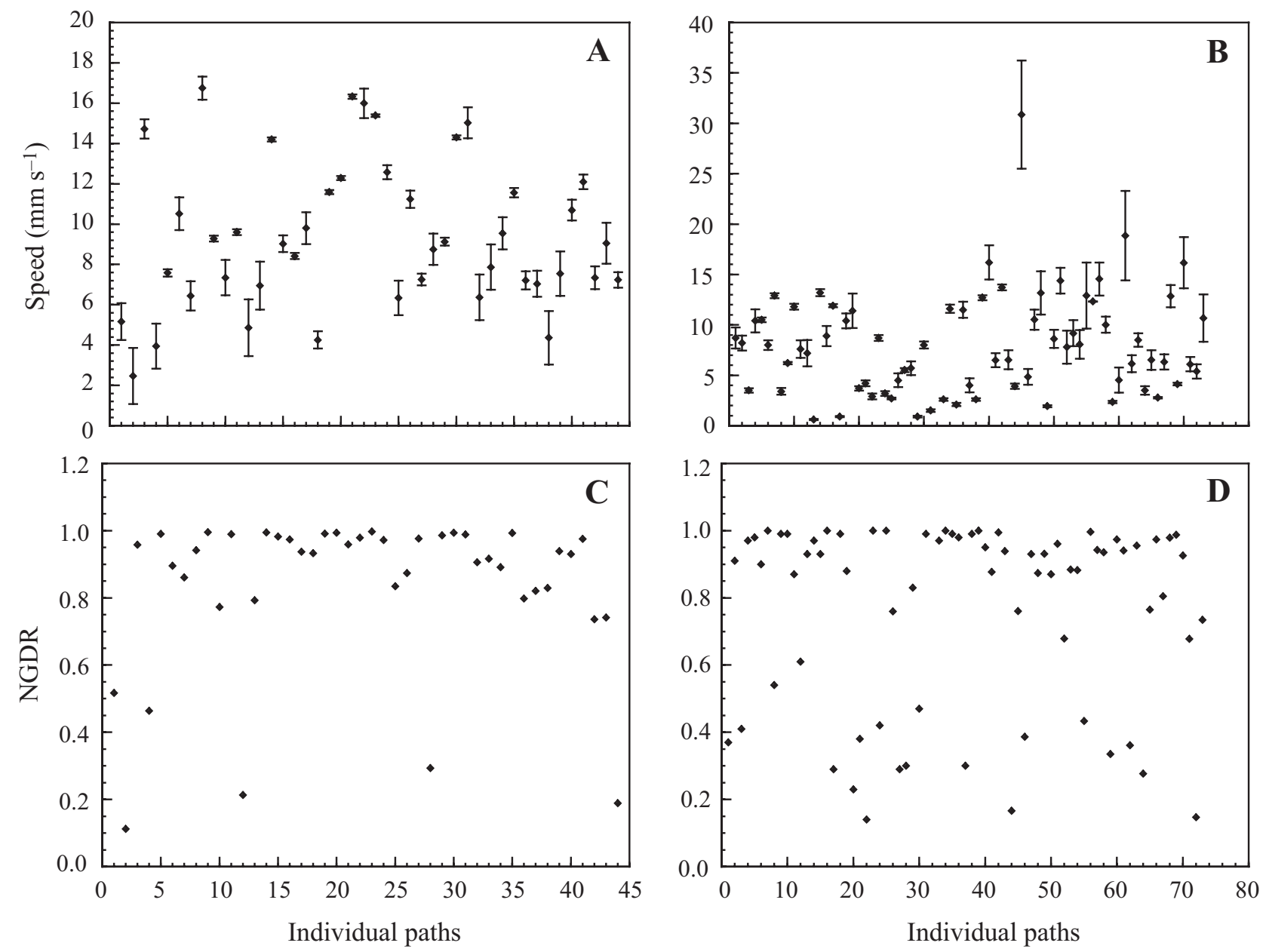

Fig. 6. Oncaea venusta. Swimming speeds and net-to-gross displacement ratios (NGDR) as a function of individual paths for males $(A, C)$ and females (B, D). Error bars are SD

\section{Fractal dimension}

Log-log plots of $N(\lambda)$ versus $\lambda$ exhibited a very strong linear behavior for males (Fig. 7A) and females (Fig. 7B) over the whole range of available scales (i.e. from 1 to $200 \mathrm{~mm}$ ) with coefficient of determination $\mathrm{r}^{2}$ ranging from 0.98 to 0.99 . A clear scaling behavior was observed from 1 to $200 \mathrm{~mm}$ for the 44 individual male paths and 66 of the female paths. In addition, 6 of the female paths showed 2 distinct scaling behaviors at scales smaller and larger than $10 \mathrm{~mm}$ (Fig. 8). This third group is hereafter referred to as $G_{10}$. The shortest female path (No. 32) did not exhibit any scaling behavior because of the small number of data points (i.e. $\mathrm{n}=19$ ). The resulting fractal dimensions, plotted as a function of individual paths (Fig. 9), showed a lower inter-individual variability for males (Fig. 9A) than for females (Fig. 9B). Nevertheless the male and female fractal dimensions $\left(D_{\mathrm{m}}\right.$ and $\left.D_{\mathrm{f}}\right)$, averaging $D_{\mathrm{m}}=1.14 \pm 0.06($ mean $\pm \mathrm{SD})$ and $D_{\mathrm{f}}=1.15 \pm$

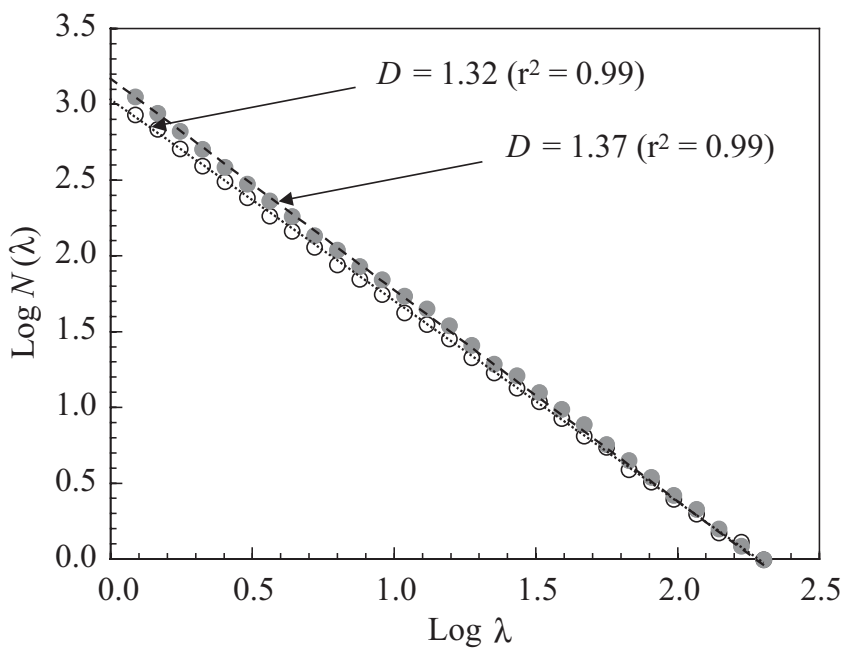

Fig. 7. Oncaea venusta. Illustration of the scaling behavior of the $\log -\log$ plots of $N(\lambda)$ versus $\lambda$ for the individual male Path 44 (closed symbols) and the female Path 59 (open symbols) 


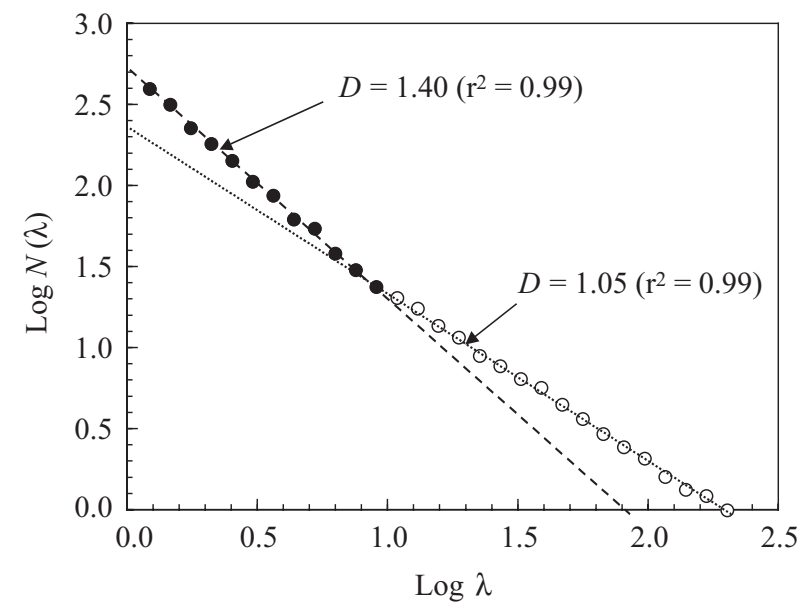

Fig. 8. Oncaea venusta. Illustration of the 2 distinct scaling behaviors of the log-log plots of $N(\lambda)$ versus $\lambda$ for the individual female Path 42

0.06, cannot be statistically distinguished (WMW test, $\mathrm{p}>0.05$ ). The fractal dimensions of the 2 types of path for the $G_{10}$ group $D_{>10}=1.35 \pm 0.05$ (mean $\pm \mathrm{SD}$ ) and $D_{<10}=1.02 \pm 0.01$ were significantly different from each other (WMW test, $\mathrm{p}<0.01$ ). These 2 groups of fractal dimensions $\left(D_{>10}\right.$ and $\left.D_{<10}\right)$ corresponded to Paths 8, 42, 66-68 and 70. As observed for swimming speeds and NGDRs, the distributions of the fractal dimensions among individual paths were characterized by an elevated individual variability (Fig. 9). CV in the individual fractal dimensions ranged from 0.01 to 0.19 for males and from 0.00 to 0.16 for females. CV between individual fractal dimensions was 0.056 for males and 0.049 for females.

As the fractal dimensions were significantly different within males and females (KW test, $\mathrm{p}<0.01$ ), the origin of the observed variability in fractal dimensions was more thoroughly investigated using the Jonckheere test for ordered alternatives (Siegel \& Castellan 1988) to identify distinct groups of fractal dimensions. Four groups of significantly different fractal dimensions $D_{\mathrm{m}}$ were identified for the male paths (Fig. 9A). These groups were classified by decreasing fractal dimension values as: $G_{\mathrm{m} 1}$ (Paths 12, 27, 35), $G_{\mathrm{m} 2}$ (Paths 1, 2, 4), $G_{\mathrm{m} 3}$ (Paths 3, 6-8, 13-26, 28-34, 36-44) and $G_{\mathrm{m} 4}$ (Paths 5, $9,11)$. Three groups were identified for female paths (Fig. 9B) and classified by decreasing fractal dimension values as $G_{\mathrm{f} 1}$ (Paths 1, 3, 17, 20, 28, 59), $G_{\mathrm{f} 2}$ (Paths 2, $4-7,9-12,13-16,18-19,21-27,29-31,34-41,43-58$, $60-65,69,71-73)$ and $G_{\mathrm{f} 3}$ (Path 33). The fractal dimensions of groups $G_{\mathrm{f} 1}$ and $G_{\mathrm{f} 2}$ were, respectively, significantly smaller and higher than the fractal dimensions of groups $G_{>10}$ and $G_{<10}$ (Jonckheere test, p < 0.05). The fractal dimensions of groups $G_{\mathrm{f} 3}$ and $G_{<10}$ were not significantly different (Jonckheere test, $\mathrm{p}<0.05$ ).

\section{Correlation analyses}

Correlation analyses were done between the number of data points in each individual swimming trajectory, swimming speed, NGDR and fractal dimensions for males and females (1) to infer the potential effect of the length of an individual swimming path on the estimates of behavioral metrics and (2) to investigate the relationships between these metrics for males and females. The analyses showed that swimming speed and NGDR were significantly negatively correlated with the length of the trajectories for males and females, while fractal dimensions were not (Table 2). Swimming speed and NGDR were significantly positively correlated, and fractal dimensions and NGDR were significantly negatively correlated (Table 2 ).

\section{DISCUSSION}

\section{Robustness of fractal dimension estimates}

Fielding (1992), Hastings \& Sugihara (1993), Kenkel \& Walker (1993) and Seuront et al. (2004b) previously suggested that to ensure the meaning and the reliability of fractal dimension estimates, different methods should be used on the same data sets. Here, we used a method conceptually similar to the box-counting procedure, i.e. the compass procedure. Using this procedure, the fractal dimension is estimated by measuring the length $L$ of a path at various scale values $\delta$. This approach was initially introduced by Richardson (1961) to measure the length of the coast of Brittany. He showed that this length is not defined as an absolute value, but has a length varying with the resolution used for the measurements. This was later conceptualized as a frac-

Table 2. Oncaea venusta. Correlation matrix of variables relative to the behavior of males and females of the copepod (time: duration of the swimming paths of $O$. venusta analyzed; $v$ : mean swimming speed; NGDR net-to-gross displacement rate; $D$ : fractal dimension). ${ }^{*} 5 \%$ significance level; ${ }^{* *} 1 \%$ significance level

\begin{tabular}{|lcccc|}
\hline & Time & $V$ & NGDR & $D$ \\
\hline Males & & & & \\
Time & - & - & - & - \\
$V$ & $-0.532^{* *}$ & - & - & - \\
NGDR & $-0.323^{*}$ & $0.474^{* *}$ & - & - \\
$D$ & 0.201 & -0.264 & $-0.364^{*}$ & - \\
Females & & & & \\
Time & - & - & - & - \\
$V$ & $-0.704^{* *}$ & - & - & - \\
NGDR & $-0.400^{*}$ & $0.280^{*}$ & - & - \\
$D$ & 0.182 & -0.174 & $-0.608^{*}$ & - \\
\hline
\end{tabular}


tal dimension for movement pathways by Mandelbrot (1983), and it is also called the 'latent dimension' by Feder (1988). The procedure is analogous to moving a set of dividers (like a drawing compass) of fixed length $\delta$ along the path. The estimated length of the path is the product of $N$ (number of compass dividers required to 'cover' the object) and the scale factor $\delta$. The number of dividers necessary to cover the object then increases with decreasing measurement scale, giving rise to the power-law relationship:

$$
L(\delta)=\mathrm{k}_{2} \delta^{m}
$$

where $\delta$ is the measurement scale, $L(\delta)$ is the measured length of the path, $L(\delta)=N \delta$, and $\mathrm{k}_{1}$ is a constant. Practically, the fractal dimension $D_{c}$ is estimated from the slope $m$ of the $\log -\log$ plot of $L(\delta)$ versus $\delta$ for various values of $\delta$ where:

$$
D_{\text {c }}=1-m
$$

Hereafter, the fractal dimension $D_{\mathrm{c}}$ will be referred as the 'compass dimension'. As the values $L(\delta)=N \delta$ may vary depending on the starting position along the curve (Seuront et al. 2004 b), we obtained a distribution of the compass dimensions by repeatedly starting the compass procedure at different, randomly chosen, positions. The resulting compass dimensions $D_{\mathrm{c}}{ }^{\prime}$, estimated from 10 random starting positions for each of the 127 swimming paths available, do not show significant differences $(p>0.05)$ to the compass dimensions $D_{c}$ estimated using the first point of the paths as a starting point for the compass algorithm. This result is fully consistent with previous investigations conducted on the 3-dimensional swimming trajectories of Daphnia pulex (Seuront et al. 2004b). Further, one may also note here that the compass dimension $D_{\mathrm{c}}$ estimated for males $\left(D_{\mathrm{c}, \mathrm{m}}=1.15 \pm 0.05\right.$, mean $\left.\pm \mathrm{SD}\right)$ and females $\left(D_{\mathrm{c}, \mathrm{f}}=1.16 \pm 0.06\right)$ is not significantly different (WMW test, $\mathrm{p}>0.05$ ) from the corresponding box-counting dimensions $D$ (i.e. $D_{\mathrm{m}}=1.14 \pm$ 0.06 and $D_{\mathrm{f}}=1.15 \pm 0.06$ ); see also Fig. 10 .

In a study of the motion behavior of the marine snail Littorina littorea, Erlandson \& Kostylev (1995) showed that the values of box-counting dimensions might be positively correlated to path length. This limitation of the box-counting method has been addressed by comparing the box-counting dimensions obtained from our 44 and 72 male and female swimming paths of different length. The resulting box-counting dimensions $D^{\prime}$ did not show any significant differences between the

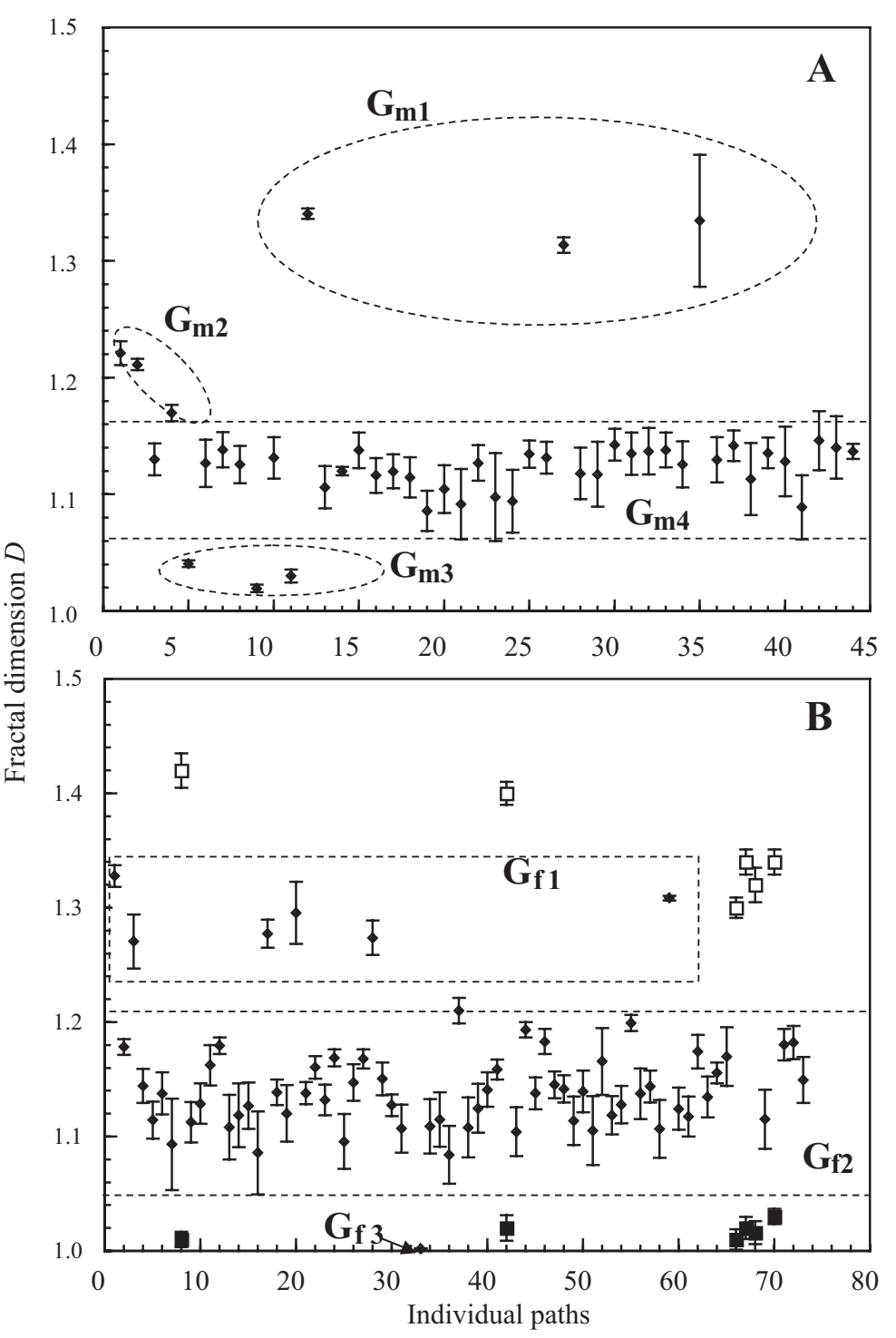

Fig. 9. Oncaea venusta. Fractal dimension $D$ as a function of individual paths for males (A) and females (B). The black rhombi are the fractal dimensions estimated for male and female individual paths when scaling behavior occurred over the whole range of available scales. The open and black squares are the fractal dimensions estimated for the 6 female paths exhibiting 2 scaling behaviors for scales >10 and <10 mm (G10 group). Error bars are SD

126 available paths (covariance analysis, F-test, p > 0.05). These results thus ensure the relevance of our fractal dimension estimates.

\section{Scale-dependent versus scale-independent metrics in behavioral studies}

The intrinsic weakness related to the scale dependence of standard behavioral metrics (swimming speed and NGDR) has been discussed extensively in Seuront et 

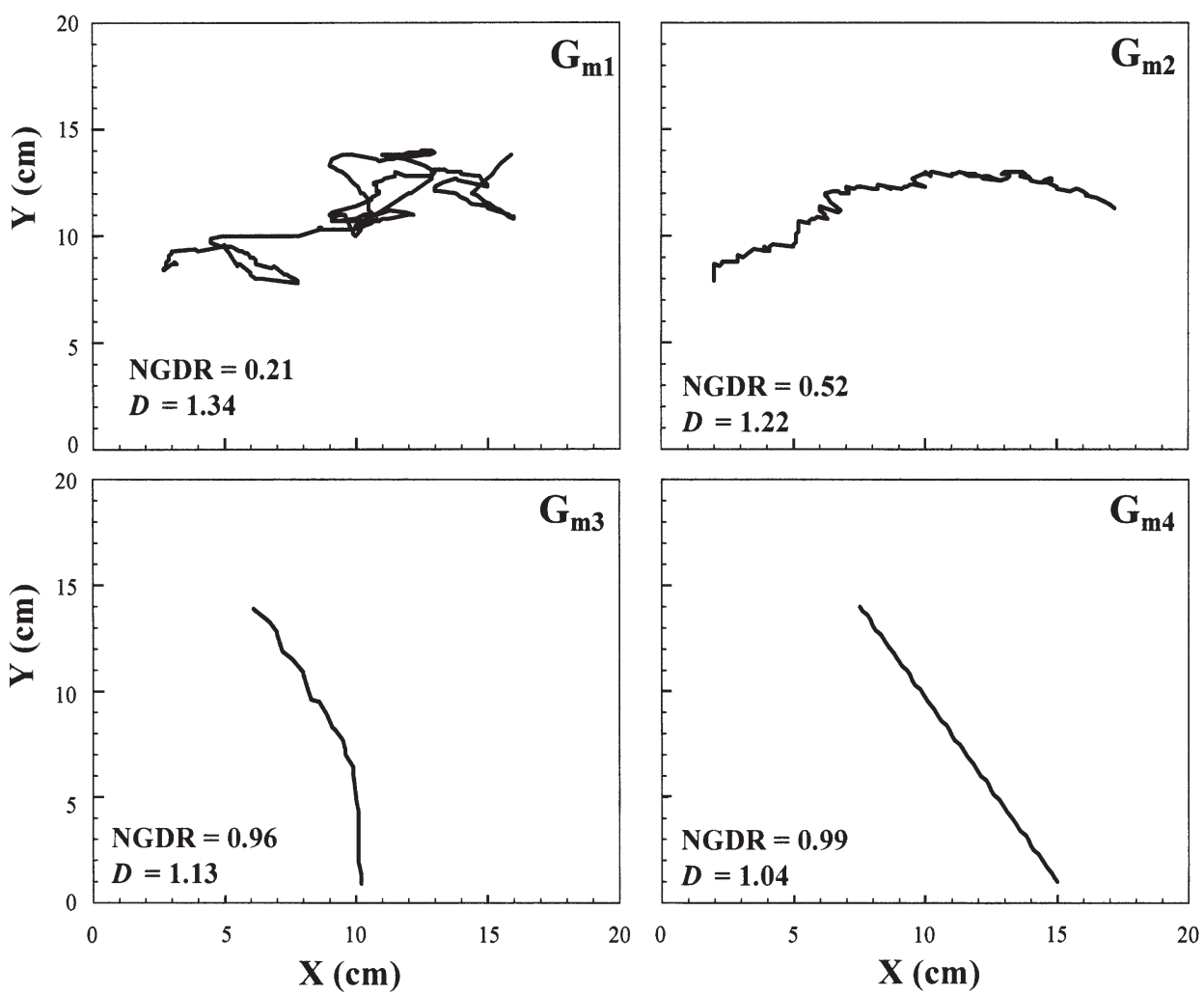

Fig. 10. Oncaea venusta. Illustration of the values taken by the net-to-gross displacement ratios (NGDR) and fractal dimension for swimming paths characteristic of the 4 distinct groups of behavior identified for males

al. (2004b). Here, we focused on the relevance of the differential information related to estimates of swimming speed, NGDR and fractal dimension, in terms of quantifying and classifying behavioral strategies. Fractal dimension thus appeared to be the most relevant behavioral metric for several critical reasons, aside from its scale-independent nature. First, fractal dimension is independent of the length of the swimming path (see Table 2), as previously suggested elsewhere (Seuront et al. 2004b). Second, the significantly lower intra- and inter-individual variability in fractal dimensions compared to swimming speed and NGDR suggests that the fractal dimension is more likely to identify slight differences in zooplankton behavior. This indeed seems to be the case here as fractal dimension allowed us: (1) to refine the initial qualitative, visual classification of swimming paths, e.g. the 'A-shaped' and 'V-shaped' swimming paths did not exhibit specific fractal properties, but were instead included in the $G_{\mathrm{m} 3}$ and $G_{\mathrm{f} 2}$ groups, (2) to identify, on the basis of objective statistical criteria, different groups of copepods within males and females (Figs. 11, 12) that could not have been distinguished using swimming speed and NGDR alone (compare Figs. 6, 9) and (3) to diagnose the presence of different levels of organization within an a priori rectilinear, swimming path (see Fig. $10 G_{\mathrm{m} 3}$ and $G_{\mathrm{m} 4}$ and Fig. $11 G_{\mathrm{f} 3}$ and $G_{10}$ ). This is a desirable feature, as behavioral shifts in copepods relative to e.g. age (Van Duren \& Videler 1995), mating (Van Duren \& Videler 1996, Doall et al. 1998) and food quality and quantity (Tiselius 1992, Kiørboe et al. 1996), which can be limited to different combinations of hovering, hopping and cruising modes, were not necessarily detected using conventional behavioral metrics such as NGDR (Van Duren \& Videler 1995, 1996, Tiselius 1992). In addition, the identification of 4 groups of swimming patterns for males and females investigated under the same laboratory conditions may suggest ontogenic differences in the food, light and temperature history of different groups or individuals. Further investigations are nevertheless needed to improve the relevance and to ensure the generality of the above arguments to other species of copepods, in different trophic and physical environments.

\section{Zooplankton swimming and randomness}

An important consequence of the fractal nature of zooplankton swimming behavior is its clear deviation from Brownian motion. Brownian motion, which can 

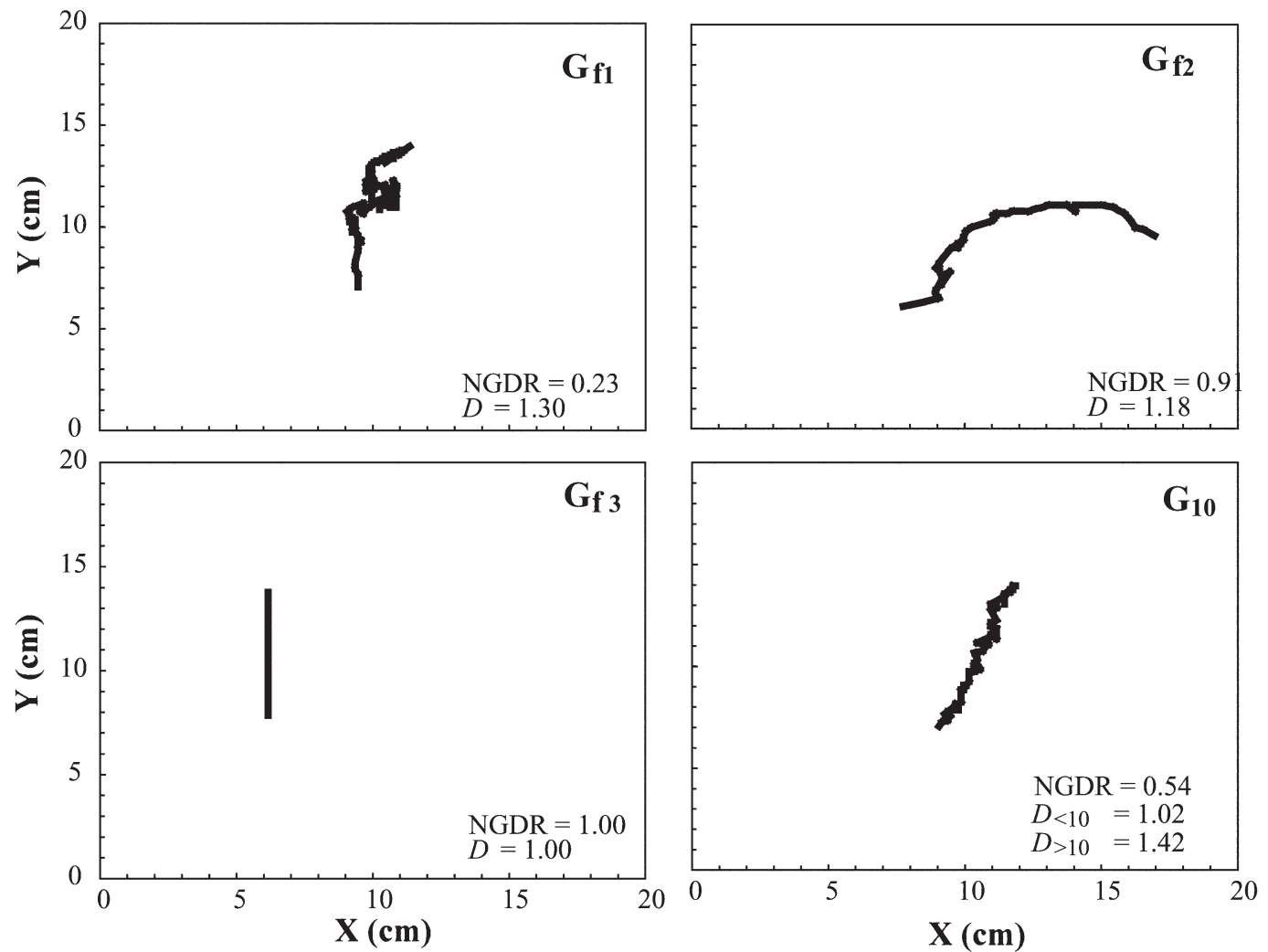

Fig. 11. Oncaea venusta. Illustration of the values taken by the NGDR and fractal dimension for swimming paths characteristic of the 4 distinct groups of behavior identified for females

be equivalently referred to as a normal diffusion process, is characterized by its space-filling properties and a related fractal dimension of $D=2.00$. Brownian motion models have been suggested to characterize the movement of organisms (Berg 1983, Frontier 1987). However, Wiens \& Milne (1989), examining beetle movements in natural fractal landscapes, found that observed beetle movements deviated from the mod- eled (Brownian) ones. Johnson et al. (1992) found that beetle movements reflect a combination of ordinary (random) and anomalous diffusions. To our knowledge all studies devoted to the study of the fractal behavior of freshwater and marine microzooplankton, zooplankton, or ichtyoplankton organisms never found any Brownian motion (Coughlin et al. 1992, Bundy et al. 1993, Brewer 1996, Jonsson \& Johansson 1997, Dowl-
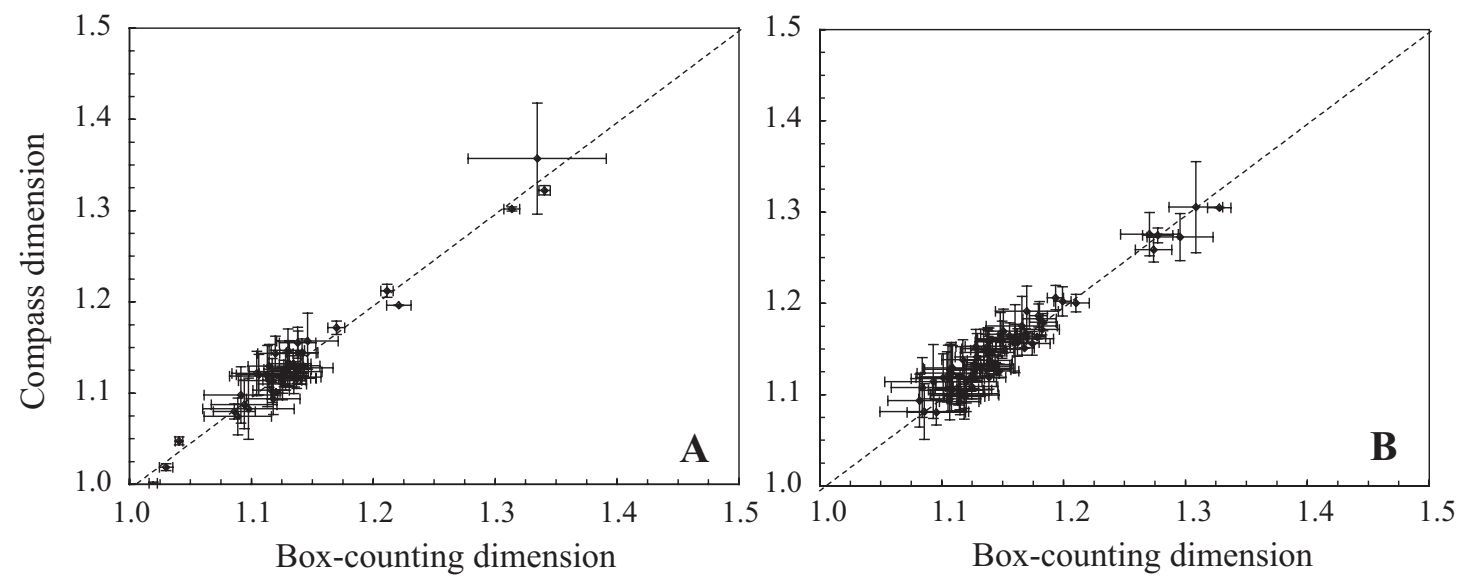

Fig. 12. Oncaea venusta. Comparison between the fractal dimensions obtained using the box-counting and the compass procedures, for males (A) and females (B) 
ing et al. 2000, Schmitt \& Seuront 2001, 2002, Bartumeus et al. 2003, Faure et al. 2003, Seuront et al. $2004 a, b, c)$. This suggests that non-Brownian (or anomalous diffusion; see Schmitt \& Seuront 2001, Seuront et al. 2004c) swimming could be the rule, rather than the exception, in aquatic ecology, as such strategies have been shown to be much more efficient than random motion in terms of foraging success (Viswanathan et al. 1999, Bartumeus et al. 2002).

The latter may simply reflect intrinsic departures from randomness, or result from barrier avoidance and utilization of corridors in natural landscapes. An extensive discussion of the anomalous (i.e. non-Brownian) diffusion of a copepod in a heterogeneous environment can be found elsewhere (Marguerit et al. 1998, Schmitt \& Seuront 2001, 2002, Seuront et al. 2004c). Future modeling of zooplankton swimming behavior may thus have to take into account the non-randomness (i.e. fractal) of organisms' movements and the persistence of the direction of travel, as recently suggested by Schmitt \& Seuront (2001), Wu et al. (1999) and Seuront et al. (2004c).

\section{Ecological relevance of multiple-scaling behavior}

Because different scales are often associated with different driving processes (Wiens 1989, Seuront \& Lagadeuc 1997), the fractal dimension may have the desirable feature of only being constant over a finite, instead of an infinite, range of measurement scales. It is then useful for: (1) identifying characteristic scales of variability and (2) comparing movements of organisms that may respond, for instance, to the patchy structure of their environment at different absolute scales. Changes in the value of $D$ with scale may indicate that a new set of environmental or behavioral processes are controlling movement behavior (e.g. decreased influence of patch barriers or the effect of home range behavior). Thus, the scale dependence of the fractal dimension over finite ranges of scales may carry more information, both in terms of driving processes and sampling limitation, than its scale independence over the whole range of available scales. In the present case, the observed change in fractal dimensions above and below a critical scale of $10 \mathrm{~mm}$ for group $G_{10}$ is indicative of a combination of 2 distinct swimming modes operating at different spatial scales. As the fractal dimension of the swimming path for the scale $>10 \mathrm{~mm}(D=$ $1.002 \pm 0.001$, mean $\pm \mathrm{SD}$ ) is not significantly different from the value expected in the case of strict linear swimming, $D=1.00$, it could reasonably be related to a cruising mode. The more complex behavior observed for scales $<10 \mathrm{~mm}(D=1.42 \pm 0.01)$ could thus be related to a microscale searching mode relative to local chemical and/or physical stimuli. As only 6 of the $72 \mathrm{fe}-$ males investigated here exhibited such a bimodal behavior, more experimental work is needed to investigate its origin.

While the occurrence of slope change may indicate the operational scale of different generative processes, it may also reflect the limited spatial resolution of the data being analyzed (Hamilton et al. 1992, Kenkel \& Walker 1993, Gautestad \& Mysterud 1994). However, as previously shown in Daphnia pulex trajectories (Seuront et al. 2004b, their Fig. 5), the effect of spatial resolution in the data will manifest itself as a gradual change of the fractal dimensions towards $\mathrm{D} \rightarrow 1$ or $\mathrm{D} \rightarrow 2$, and cannot be confused with a transition zone between 2 different scaling regions. What is critical for a proper interpretation of fractal dimensions is then to identify the range of scales over which the fractal dimension is invariant.

\section{Zooplankton behavior and the structure of the environment}

In light of the growing awareness of the scaling nature of marine ecosystems, in both their physical and biological aspects (e.g. Pascual et al. 1995, Seuront et al. 1996a,b, 1999, 2002, Seuront \& Lagadeuc 1997, 1998, 2001, Seuront \& Schmitt 2001, Lovejoy et al. 2001), it is becoming increasingly necessary to find a way to compare the composition of zooplankton swimming behaviors in relation to phytoplankton distributions. Considering the remote sensing ability of zooplankton, their behavior could be strongly influenced by the distribution of their phytoplankton prey. While, it is not yet possible to obtain 3-dimensional, microscale (i.e. scales $<1 \mathrm{~m}$ ) distributions of phytoplankton cells in situ, it is feasible to obtain prolonged, simultaneous 1-dimensional records (i.e. vertical profiles and time series) of physical (shear, temperature, salinity) and biological (in vivo fluorescence, backscatter) parameters at scales of $<1 \mathrm{~m}$ (see e.g. Wolk et al. 2002, 2004). From such records, one may expect a 1 -dimensional fractal dimension of phytoplankton distribution of $D=0.67$ (Seuront \& Lagadeuc 1997, Seuront et al. 2002). In the present study, we found 2-dimensional fractal dimensions $D_{\mathrm{m}}=1.14 \pm 0.06$ and $D_{\mathrm{f}}=1.15 \pm 0.06$ for males and females of Oncaea venusta, respectively. Unfortunately, a direct comparison of these 2 dimensions is not possible, because they characterize 2 processes embedded in different dimensions (Roy et al. 1987, Huang \& Turcotte 1989, Seuront et al. 2004b). A more fundamental framework, the fractal codimension, has been introduced to make possible comparisons of the structure of patterns and processes embedded in different $d$-dimensional spaces. The fractal codimension $c$ has been defined as: 


$$
C=d-D
$$

where $d$ is the Euclidean dimension of the embedding space and $D$ the fractal dimension of the pattern/process under consideration (for ecological applications see Seuront et al. 1999, 2004b). The fractal codimension measures the fraction of the space occupied by the process of interest, and is bounded between $c=0$ and $C=1$ for 'standard' processes characterized by a fractal dimension $D$ such as $d-1 \leq D \leq d$. The fractal dimension $D$ of swimming paths is intrinsically bounded between $1 \leq D \leq 2$, whatever the value of the embedded dimension $d$. For more generality we can thus consider a fractal codimension bounded between $c=0$ and $c=d$. However, in such a framework, comparisons of codimensions estimated from processes embedded in different $d$-dimensional spaces are unfeasible without an a priori knowledge of the embedding dimension $d$. The fractal codimension subsequently provides only a relative measure of sparseness. The 'path codimension' c' (Seuront et al. 2004b):

$$
C^{\prime}=c / d
$$

has thus been introduced as an absolute measure of sparseness. $C^{\prime}$ is bounded between $C^{\prime}=0$ for space-filling processes and $C^{\prime}=1$ for processes so sparse that their fractal dimension is nil, whatever the values of the original embedding dimensions $d$ may be. The path codimensions of a phytoplankton distribution characterized by a fractal dimension of $D=0.67$ is $C^{\prime}=$ 0.33 . The path codimension of the swimming behaviors of males and females of Oncaea venusta are $c^{\prime}=0.430$ and $C^{\prime}=0.425$, respectively. The swimming behavior of $O$. venusta is thus less complex (or less space filling) than the distribution of its phytoplankton prey. In particular, this result fully agrees with studies demonstrating the differences in motility between predator and prey (e.g. Tiselius et al. 1993, 1997, Abraham 1998, Seuront \& Lagadeuc 2001). However, O. venusta also feed on marine snow (Alldredge 1972), detritic materials (Yamaguchi et al. 2002), chaetognaths and appendicularians (Go et al. 1998). The swimming behavior of $O$. venusta might then be more complex than the distribution of phytoplankton cells; to confirm this, further behavioral investigations would be needed in the presence of the different food sources.

\section{Consequences of fractal swimming behavior}

The identification of 4 groups of males and females with significantly different fractal dimensions suggests that, within the same species, different individuals are susceptible to develop specific behavior in relation with local variability in e.g. food availability that may request enough behavioral plasticity to exploit very specific ecological niches such as those related to microzones and microscale patches (Mitchell et al. 1985, Azam 1998). According to the optimal foraging theory (Pyke 1984), zooplankton organisms are expected to optimize the energy required to capture a given amount of food. As the distance travelled between 2 points, and then the related energy expenditure, increases with increasing fractal dimensions, it could also be used as a foraging index. More generally, the path codimension provides a method of comparing the complexity of 2 interrelated processes, each of which may be embedded in a different dimensional space. Future investigations of zooplankton swimming behavior could thus take advantage of this method to systematically investigate the fractal nature of its prey to infer more detailed causality in predator-prey interactions.

\section{Variability in zooplankton swimming behavior}

According to the high intra- and inter-individual variability observed in the swimming paths of both males and females of the copepod Oncaea venusta (see Figs. 6, 9), it seems difficult to infer any causality in their behavior. However, some studies indicated that various species of Oncaea are omnivorous (Turner 1986). Although O. venusta can clearly feed on suspended motile cells (Turner \& Tester 1989, Wu et al. 2004), Oncaea spp. are also known to feed on material attached to surfaces, such as marine snow (Alldredge 1972), and some authors have considered the genus Oncaea to be detritivore (Yamaguchi et al. 2002). On the other hand, Go et al. (1998) showed that O. venusta and 2 other congeneric species from the south of the Korean Peninsula can feed on much larger zooplankton species, such as chaetognaths and appendicularians. They showed that these species (Oncaea spp.) exhibit a complex swimming behavior when attacking chaetognaths. The observed variability in $O$. venusta swimming patterns could thus be related to the diversity of feeding modes characterizing this species. Further behavioral investigations, in particular on individuals fully acclimatized for several generations in the laboratory to specific food sources, are nevertheless needed to clarify this hypothesis.

\section{Conclusions}

The current study identified a challenging high intra- and inter-individual variability, probably related to the omnivorous feeding behavior of Oncaea venusta, that still needs to be investigated thoroughly. 
In particular, one has to remember that this preliminary work does not address the potential differences in behavior between a still-water container in the laboratory and a real-world turbulent environment, where copepods must search for food while at the same time avoiding predation and finding a mate. We nevertheless clearly demonstrated that fractal analysis is a powerful tool to investigate thoroughly the intra- and inter-individual variability in zooplankton swimming behavior. In particular, fractal dimensions are less sensitive than standard behavioral metrics (swimming speed and NGDR) to technical and biological limitations, such as the number of available data points and individual variability. Individual swimming behavior is (1) the underlying mechanism generating population level behaviors, such as horizontal and vertical migration (e.g. Folt \& Burns 1999); (2) likely to affect the outcome of predator-prey interactions, especially in the pelagic environment, where prey movement is important both as a cue to predators (Brewer \& Coughlin 1995) and a determinant of encounter rate (Gerritsen \& Strickler 1977); and (3) linked to individual feeding rates in most zooplankton species (Kiørboe et al. 1996, Caparroy et al. 1998), and we believe that the journey of 'behavioral fractals' to elucidate zooplankton behavior complexity is still in its infancy.

Acknowledgements. We are grateful to the crew on board the 'Ocean Research Vessel II' for assistance, to $\mathrm{PhD}$ students Wen-Hung Twan and Shao-Hung Peng from the National Taiwan Ocean University for help with the experiments, to Prof. Chang-tai Shih for his sorting of live specimens of Oncaea venusta and to Dr. J.R. Strickler for the supervision of the laser video optical technique. R. Waters is gratefully acknowledged for her constructive comments on an earlier version of this work, as well as for improving the language. J.R. Seymour and M.J. Doubell are acknowledged for their discussions and the invaluably stimulating framework developed within the Muppet squad. This research was partially supported by the National Science Council and Ministry of Education, Taiwan, ROC, to J.S. Hwang. This work is a contribution to the Ecosystem Complexity Research Group.

\section{LITERATURE CITED}

Abraham ER (1998) The generation of plankton patchiness by turbulent stirring. Nature 391:577-560

Alldredge AL (1972) Abandoned larvacean houses: unique food sources in the pelagic environment. Science 177: 885-887

Appleby S (1996) Multifractal characterization of the distribution pattern of the human population. Geogr Anal 28: $147-160$

Azam F (1998) Microbial control of oceanic carbon flux: the plot thickens. Science 280:694-696

Bartumeus F, Catalan J, Fulco UL, Lyra ML, Viswanathan GM (2002) Optimizing the encounter rate in biological interactions: Lévy versus Brownian strategies. Physiol Rev Lett 88:97901-97904
Bartumeus F, Peters F, Pueyo S, Marrasé C, Catalan J (2003) Helical Lévy walks: adjusting searching statistics to resource availability in microzooplankton. Proc Natl Acad Sci USA 100:12771-12775

Berg HC (1983) Random walk in biology. Princeton University Press, Princeton, NJ

Brewer MC (1996) Daphnia swimming behavior and its role in predator-prey interactions. PhD thesis, University of Wisconsin, Milwaukee

Brewer MC (1998) Mating behaviours of Daphnia pulicaria, a cyclic parthenogen: comparisons with copepods. Philos Trans R Soc Lond B 353:805-815

Brewer MC, Coughlin JN (1995) Virtual plankton: a novel approach to the investigation of aquatic predator-prey interactions. Mar Freshw Behav Physiol 26:91-100

Buchanan C, Goldberg B, McCartney R (1982) A laboratory method for studying zooplankton swimming behaviors. Hydrobiol 94:77-89

Bundy MH, Gross TF, Coughlin DJ, Strickler JR (1993) Quantifying copepod searching efficiency using swimming pattern and perceptive ability. Bull Mar Sci 53:15-28

Buskey EJ (1984) Swimming pattern as an indicator of the roles of copepod sensory systems in the recognition of food. Mar Biol 79:165-175

Buskey EJ (1997) Behavioral components of feeding selectivity of the heterotrophic dinoflagellate Prorocentrum pellucidum. Mar Ecol Prog Ser 153:77-89

Buskey EJ, Stoecker DK (1988) Locomotory patterns of the planktonic ciliate Favella sp.: adaptations for remaining within food patches. Bull Mar Sci 43:783-796

Buskey EJ, Mills L, Swift E (1983) The effects of dinoflagellate bioluminscence on the swimming behavior of a marine copepod. Limnol Oceanogr 28:575-579

Buskey EJ, Coulter C, Strom S (1993) Locomotory patterns of microzooplankton: potential effects on food selectivity of larval fish. Bull Mar Sci 53:29-43

Buskey EJ, Peterson JO, Ambler JW (1996) The swarming behavior of the copepod Dioithona oculata: in situ and laboratory studies. Limnol Oceanogr 41:513-521

Caparroy P, Pérez MT, Carlotti F (1998) Feeding behaviour of Centropages typicus in calm and turbulent conditions. Mar Ecol Prog Ser 168:109-118

Charoy CP, Janssen CR, Persoone G, Clément P (1995) The swimming behaviour of Brachiomus calyciflorus (rotifer) under toxic stress. I. The use of automated trajectometry for determining sub-lethal effects of chemicals. Aquat Toxicol 32:271-282

Chen QC, Wong CK, Tam PF, Lee CNW, Yin JQ, Huang LM, Tam YH (2003) Variations in the abundance and structure of the planktonic copepod community in the Pearl River estuary, China. In: Morton B (ed) Perspectives on marine environment change in Hong Kong and southern China, 1977-2001. Hong Kong University Press, Hong Kong, p 389-400

Costello JH, Strickler JR, Marrasé C, Trager G, Zeller R, Freise AJ (1990) Grazing in a turbulent environment: behavioral response of a calanoid copepod, Centropages hamatus. Proc Natl Acad Sci USA 87:1648-1652

Coughlin DJ, Strickler JR, Sanderson B (1992) Swimming and search behaviour in clownfish, Amphiprion perideraion, larvae. Anim Behav 44:427-440

Cowles TJ, Desiderio RA, Carr ME (1998) Small-scale planktonic structure: persistence and trophic consequences. Oceanography 11:4-9

Doall MH, Colin SP, Strickler JR, Yen J (1998) Locating a mate in 3D: the case of Temora longicornis. Philos Trans R Soc Lond B 353:681-689 
Doall M, Strickler JR, Fields D, Yen J (2003) Mapping the free-swimming attack volume of a planktonic copepod, Euchaeta rimaria. Mar Biol 140:871-879

Dodson S, Ramcharan C (1991) Size specific swimming behavior of Daphnia pulex. J Plankton Res 13:1367-1379

Dodson SI, Ryan S, Tollrian R, Lampert W (1997) Individual swimming behavior of Daphnia: effects of food, light and container size in four clones. J Plankton Res 19:1537-1552

Dowling NA, Hall SJ, Mitchell JG (2000) Foraging kinematics of barramundi during early stages of development. J Fish Biol 57:337-353

Erlandson J, Kostylev V (1995) Trail following, speed and fractal dimension of movement in a marine prosobranch, Littorina littorea, during a mating and a non-mating season. Mar Biol 122:87-94

Faure P, Neumeister H, Faber D, Korn H (2003) Symbolic analysis of swimming trajectories reveals scale invariance and provides a model for fish locomotion. Fractals 11: 233-243

Feder J (1988) Fractals. Plenum Press, New York

Fielding A (1992) Applications of fractal geometry to biology. Comput Appl Biosci 8:359-366

Fisher R, Bellwood DR, Job SD (2000) Development of swimming abilities in reef fish larvae. Mar Ecol Prog Ser 202:163-173

Folt CL, Burns CW (1999) Biological drivers of plankton patchiness. Trends Ecol Evol 14:300-305

Frontier S (1987) Applications of fractal theory to ecology. In: Legendre P, Legendre L (eds) Developments in numerical ecology. Springer, Berlin, p 335-378

Gautestad AO, Mysterud I (1994) Physical and biological mechanisms in animal movement processes. J Appl Ecol 30:523-535

Gerritsen J, Strickler JR (1977) Encounter probabilities and community structure in zooplankton: a mathematical model. J Fish Res Board Can 34:73-82

Go YB, Oh BC, Terazaki M (1998) Feeding behavior of the poecilostomatoid copepods Oncaea spp. on chaetognaths. J Mar Syst 15:475-482

Gries T, Jöhnk K, Fields D, Strickler JR (1999) Size and structure of 'footprints' produced by Daphnia: impact of animal size and density gradients. J Plankton Res 21:509-523

Hamilton SK, Melack JM, Goodchild MF, Lewis WM (1992) Estimation of the fractal dimension of terrain from lake size distributions. In: Carling PA, Petts GE (eds) Lowland floodplain rivers: geomorphological perspectives. Wiley \& Sons, New York, p 145-163

Hastings HM, Sugihara G (1993) Fractals. A user's guide for the natural sciences. Oxford University Press, Oxford

Hsieh CH, Chiu TS (2002) Summer spatial distribution of copepods and fish larvae in relation to hydrography in the northern Taiwan Strait. Zool Stud 41:85-98

Huang J, Turcotte DL (1989) Fractal mapping of digitized images: application to the topography of Arizona and comparisons with synthetic images. J Geophys Res 94: 7491-7495

Hwang JS, Strickler JR (1994) Effects of periodic turbulent events upon escape responses of a calanoid copepod, Centropages hamatus. Bull Plankton Soc Jpn 41:117-130

Hwang JS, Strickler JR (2001) Can copepods differentiate prey from predator hydromechanically? Zool Stud 40:1-6

Hwang JS, Turner JT (1995) Behavior of cyclopoid, harpacticoid and calanoid copepods from coastal waters of Taiwan. PSZN I: Mar Ecol 16:207-216

Hwang JS, Turner JT, Costello JH, Coughlin DJ, Strickler JR (1993) A cinematographic comparison of behavior by the calanoid copepod Centropages hamatus: tethered versus free-swimming animals. J Exp Mar Biol Ecol 167:277-288 Hwang JS, Costello JH, Strickler JR (1994) Copepod grazing in a turbulent flow: elevated foraging behavior and habituation of escape responses. J Plankton Res 16:421-431

Hwang JS, Yen J, Strickler JR (1998) Research on copepods with small scale and large scale methods. Life Sci Newsl 12:6-8 (in Chinese)

Jiang $H$ (2004) Numerical simulation of the flow field at the scale size of an individual copepod. In: Seuront L, Strutton PG (eds) Handbook of scaling methods in aquatic ecology: measurement, analysis, simulation. CRC Press, Boca Raton, p 333-359

Johnson AR, Milne BT, Wiens JA (1992) Diffusion in fractal landscapes: simulations and experimental studies of tenebrionid beetle movements. Ecology 73:1968-1983

Jonsson PR, Johansson M (1997) Swimming behaviour, patch exploitation and dispersal capacity of a marine benthic ciliate in flume flow. J Exp Mar Biol Ecol 215:135-153

Keiyu AY, Yamazaki H, Strickler R (1994) A new modelling approach for zooplankton behaviour. Deep-Sea Res I 41: 171-184

Kendall M (1976) Time-series, 2nd edn. Charles Griffin, London

Kendall M, Stuart A (1966) The advanced theory of statistics. Hafner, New York

Kenkel NC, Walker DJ (1993) Fractals and ecology. Abstr Bot $17: 53-70$

Kiørboe T, Saiz E, Viitasalo M (1996) Prey switching behaviour in the planktonic copepod Acartia tonsa. Mar Ecol Prog Ser 143:65-75

Kolber ZS, Plumley FG, Lang AS, Beatty JT and 6 others (2001) Contribution of aerobic photoheterotrophic bacteria to the carbon cycle in the ocean. Science 292: 2492-2495

Lee CNW, Chen QC (2003) A historical and biogeographical analysis of the marine planktonic copepod community in Hong Kong: a record of change. In: Morton B (ed) Perspectives on marine environment change in Hong Kong and southern China, 1977-2001. Hong Kong University Press, Hong Kong, p 433-457

Lo WT, Hwang JS, Chen QC (2001) Identity and abundance of surface dwelling, coastal copepods of southwestern Taiwan. Crustaceana 74:1139-1157

Lo WT, Shih CT, Hwang JS (2004) Diel vertical migration of the planktonic copepods at an upwelling station north of Taiwan, western North Pacific. J Plankton Res 26:89-97

Lo WT, Hwang JS, Chen QC (2004) Spatial variations of copepods in the surface water of southeastern Taiwan strait. Zool Stud 43:218-228

Lovejoy S, Currie WJS, Tessier Y, Claereboudt MR, Bourget E, Roff JC, Schertzer D (2001) Universal multifractals and ocean patchiness: phytoplankton, physical fields and coastal heterogeneity. J Plankton Res 23:117-141

Maly EJ, van Leeuwen HC, Blais J (1994) Some aspects of size and swimming behavior in two species of Diaptomus (Copepoda: Calanoida). Verh Int Verein Limnol 25: 2432-2435

Mandelbrot B (1983) The fractal geometry of nature. Freeman, New York

Marguerit C, Schertzer D, Schmitt F, Lovejoy S (1998) Copepod diffusion within multifractal phytoplankton fields. J Mar Syst 16:69-83

Marrasé C, Costello JH, Granata T, Strickler JR (1990) Grazing in a turbulent environment: behavioral response of a calanoid copepod, Centropages hamatus. Proc Natl Acad Sci USA 87:1652-1657

Mitchell JG, Okubo A, Fuhrman JA (1985) Microzones sur- 
rounding phytoplankton form on the basis for a stratified marine microbial ecosystem. Nature 316:58-59

O'Keefe TC, Brewer MC, Dodson SI (1998) Swimming behavior of Daphnia: its role in determining predation risk. J Plankton Res 20:973-984

Paffenhöfer GA (1994) Variability due to feeding activity of individual copepods. J Plankton Res 16:617-626

Paffenhöfer GA, Mazzocchi MG (2002) On some aspects of the behaviour of Oithona plumifera (Copepoda: Cyclopoida). J Plankton Res 24:129-135

Paffenhöfer GA, Strickler JR, Lewis KD, Richman S (1996) Motion behavior of nauplii and early copepodid stages of marine planktonic copepods. J Plankton Res 18: $1699-1715$

Pascual M, Ascioti FA, Caswell H (1995) Intermittency in the plankton: a multifractal analysis of zooplankton biomass variability. J Plankton Res 17:1209-1232

Porter KG, Gerritsen J, Orcutt JD (1982) The effect of food concentration on swimming patterns, feeding behavior, ingestion, assimilation and respiration in Daphnia. Limnol Oceanogr 27:935-949

Price HJ (1989) Feeding mechanisms of krill in response to algal patches: a mesocosm study. Limnol Oceanogr 34: 649-659

Pyke JH (1984) Optimal foraging theory: a critical review. Annu Rev Ecol Syst 15:523-575

Ramcharan CW, Sprules WG (1991) Predator-induced behavioral defense and its ecological consequences for two calanoid copepods. Oecologia 86:276-286

Richardson LF (1961) The problem of contiguity: an appendix of statistics of deadly quarrels. Yearbook of the Society for General Systems Research, Vol III. Ann Arbor, MI, p 140-187

Ringelberg J (1964) The positively phototactic reaction of Daphnia magna Strauss: a contribution to the understanding of diurnal vertical migration. Neth $J$ Sea Res 2: 319-406

Rivkin RB, Legendre L (2001) Biogenic carbon cycling in the upper ocean: effects of microbial respiration. Science 291: 2398-2400

Roy AG, Gravel G, Gauthier C (1987) Measuring the dimension of surfaces: a review and appraisal of different methods. In: Proc 8th Int Symp Computer-assisted Cartography (Auto-Carto 8). American Congress on Surveying and Mapping, Baltimore, p 68-77

Saiz E (1994) Observations of the free-swimming behavior of Acartia tonsa: effects of food concentration and turbulent water motion. Limnol Oceanogr 39:1566-1578

Saiz E, Alcaraz M (1992) Free-swimming behaviour of Acartia clausi (Copepoda: Calanoida) under turbulent water movement. Mar Ecol Prog Ser 80:229-236

Schmitt F, Seuront L (2001) Multifractal random walk in copepod behavior. Physica A 301:375-396

Schmitt F, Seuront L (2002) Multifractal anormal diffusion in swimming behavior of marine organisms. In: Pomeau Y, Ribotta R (eds) Proc 5th Rencontre du Non-linéaire. Nonlinéaire Publications, Institut Poincarré, Paris, p 237-242

Seuront L, Lagadeuc Y (1997) Characterisation of space-time variability in stratified and mixed coastal waters (Baie des Chaleurs, Québec, Canada): application of fractal theory. Mar Ecol Prog Ser 159:81-95

Seuront L, Lagadeuc Y (1998) Spatio-temporal structure of tidally mixed coastal waters: variability and heterogeneity. J Plankton Res 20:1387-1401

Seuront L, Lagadeuc Y (2001) Multiscale patchiness of the calanoid copepod Temora longicornis in a turbulent coastal sea. J Plankton Res 23:1137-1145
Seuront L, Schmitt FG (2004) Eulerian and Lagrangian properties of biophysical intermittency in the ocean. Geophys Res Lett 31:L03306, doi: 10.1029/2003GL018185

Seuront L, Schmitt F, Schertzer D, Lagadeuc Y, Lovejoy S (1996a) Multifractal intermittency of Eulerian and Lagrangian turbulence of ocean temperature and plankton fields. Nonlinear Proc Geophys 3:236-246

Seuront L, Schmitt F, Lagadeuc Y, Schertzer D, Lovejoy S, Frontier S (1996b) Multifractal analysis of phytoplankton biomass and temperature in the ocean. Geophys Res Lett 23:3591-3594

Seuront L, Schmitt F, Lagadeuc Y, Schertzer D, Lovejoy S (1999) Universal multifractal analysis as a tool to characterize multiscale intermittent patterns: example of phytoplankton distribution in turbulent coastal waters. J Plankton Res 21:877-922

Seuront L, Schmitt F, Lagadeuc Y (2001) Turbulence intermittency, phytoplankton patchiness and encounter rates in plankton: where do we go from here? Deep-Sea Res I 48: 1199-1215

Seuront L, Gentilhomme V, Lagadeuc Y (2002) Small-scale nutrient patches in tidally mixed coastal waters. Mar Ecol Prog Ser 232:29-44

Seuront L, Yamazaki H, Souissi S (2004a) Hydrodynamic disturbance and zooplankton swimming behavior. Zool Stud 43:376-387

Seuront L, Brewer M, Strickler JR (2004b) Quantifying zooplankton swimming behavior: the question of scale. In: Seuront L, Strutton PG (eds) Handbook of scaling methods in aquatic ecology: measurement, analysis, simulation. CRC Press, Boca Raton, FL, p 333-359

Seuront L, Schmitt FG, Brewer MC, Strickler JR, Souissi S (2004c) From random walk to multifractal random walk in zooplankton swimming behavior. Zool Stud 43:498-510

Seymour JR, Mitchell JG, Pearson L, Waters RL (2000) Heterogeneity in bacterioplankton abundance from 4.5 millimetre resolution sampling. Aquat Microb Ecol 22: $143-153$

Seymour JR, Mitchell JG, Seuront L (2004) Microscale heterogeneity in the activity of coastal bacterioplankton communities. Aquat Microb Ecol 35:1-16

Shih CT, Chiu TS (1998) Copepod diversity in the water masses of the southern East China Sea north of Taiwan. J Mar Syst 15:533-542

Shih MC, Hwang JS (2000) Modified phase contrast microscopy and its applications to the observation of marine biological objects. J Mar Sci Technol 8:61-64

Siegel S, Castellan NJ (1988) Nonparametric statistics. McGraw-Hill, New York

Sokal RR, Rolf FJ (1995) Biometry. Freeman, San Francisco

Strickler JR (1970) Über das Schwimmverhalten von Cyclopoiden bei Verminderungen der Bestrahlungsstärke. Schweiz Z Hydrol 32:150-180

Strickler JR (1998) Observing free-swimming copepods mating. Philos Trans R Soc Lond B 353:671-680

Strickler JR, Hwang JS (1999) Matched spatial filters in long working distance microscopy of phase objects. In: Cheng PC, Hwang PP, Wu JL, Wong G, Kim C (eds) Focus on multidimensional microscopy. World Scientific, River Edge, NJ, p 217-239

Suchman CL (2000) Escape behavior of Acartia hudsonica copepods during interactions with scyphomedusae. J Plankton Res 22:2307-2323

Tiselius P (1992) Behavior of Acartia tonsa in patchy food environments. Limnol Oceanogr 37:1640-1651

Tiselius P, Jonsson PR (1990) Foraging behaviour of six calanoid copepods: observations and hydrodynamic 
analysis. Mar Ecol Prog Ser 66:23-33

Tiselius P, Jonsson PR, Verity PG (1993) A model evaluation of the impact of food patchiness on foraging strategy and predation risk in zooplankton. Bull Mar Sci 53:247-264

Tiselius P, Jonsson PR, Karrtvedt S, Olsen EM, Jordstad T (1997) Effects of copepod foraging behavior on predation risk: an experimental study of the predatory copepod Pareuchaeta norvegica feeding on Acartia clausi and A. tonsa (Copepoda). Limnol Oceanogr 42:164-170

Titelman J (2001) Swimming and escape behavior of copepod nauplii: implications for predator-prey interactions among copepods. Mar Ecol Prog Ser 213:203-213

Titelman J, Kiørboe T (2003a) Motility of copepod nauplii and implications for food encounter. Mar Ecol Prog Ser 247: 123-135

Titelman J, Kiørboe T (2003b) Predator avoidance by nauplii. Mar Ecol Prog Ser 247:137-149

Trager GC, Hwang JS, Strickler JR (1990) Barnacle suspensionfeeding in variable flow. Mar Biol 105:117-127

Tsuda A, Miller CB (1998) Mate-finding behaviour in Calanus marshallae Frost. Philos Trans R Soc Lond B 353:713-720

Turner JT (1986) Zooplankton feeding ecology: contents of fecal pellets of the cyclopoid copepods Oncaea venusta, Corycaeus amazonicus, Oithona plumifera and O. simplex from the northern Gulf of Mexico. PSZN I: Mar Ecol 7: 289-302

Turner JT, Tester PA (1989) Zooplankton feeding ecology: copepod grazing during an expatriate red tide. In: Cosper EM, Bricelj VM, Carpenter EJ (eds) Novel phytoplankton blooms. Causes and impacts of recurrent brown tides and other unusual blooms. Springer-Verlag, Berlin, p 359-374

Turner JT, Tester PA, Strickler JR (1993) Zooplankton feeding ecology: a cinematographic study of animal-to-animal variability in the feeding behavior of Calanus finmarchicus. Limnol Oceanogr 38:255-264

Ueda H (1991) Horizontal distribution of planktonic copepods in inlet waters. In: Uye SI, Nishida S, Ho JS (eds) Proc 4th Int Conf Copepoda. Bull Plankton Soc Jpn Spec Vol, p 143-160

Utne-Palm AC, Stiansen JE (2002) Effect of larval ontogeny, turbulence and light on attack rate and swimming activity in herring larvae. J Exp Mar Biol Ecol 268:147-170

Van Duren LA, Videler JJ (1995) Swimming behaviour of development stages of the calanoid copepod Temora longicornis at different food concentrations. Mar Ecol Prog Ser 126:153-161

Van Duren LA, Videler JJ (1996) The trade-off between feeding, mate seeking and predator-prey avoidance in copepods: behavioural responses to chemical cues. J Plankton Res 18:805-818

Van Duren LA, Stamhuis EJ, Videler JJ (1998) Reading the copepod personal ads: increasing encounter probability with hydromechanical signals. Philos Trans R Soc Lond B 353:691-700

Van Leeuwen HC, Maly EJ (1991) Changes in swimming behavior of male Diaptomus leptotus (Copepoda: Calanoida) in response to gravid females. Limnol Oceanogr 36:1188-1195

Viswanathan GM, Buldyrev SV, Havlin S, da Luz MGE, Raposo EP, Stanley HE (1999) Optimizing the success of random searches. Nature 401:911-914

Waters RL, Mitchell JG (2002) Centimeter-scale spatial struc- ture of estuarine in vivo fluorescence profiles. Mar Ecol Prog Ser 237:51-63

Waters RL, Mitchell JG, Seymour JR (2003) Geostatistical characterization of centimetre-scale structure of in vivo fluorescence. Mar Ecol Prog Ser 251:49-58

Weissburg MJ, Doall MH, Yen J (1998) Following the invisible trail: kinematic analysis of mate tracking in the copepod Temora longicornis. Philos Trans R Soc Lond B 353: 701-712

Wiens JA (1989) Spatial scaling in ecology. Funct Ecol 3: 385-397

Wiens JA, Milne BT (1989) Scaling of 'landscapes' in landscape ecology, or landscape ecology from a beetle's perspective. Landsc Ecol 3:87-96

Williamson CE (1981) Foraging behavior of a freshwater copepod: frequency changes in looping behavior at high and low prey densities. Oecologia 50:332-336

Wilson RS, Greaves JOB (1979) The evolution of the bugsystem: recent progress in the analysis of bio-behavioral data. In: Jacoff FS (ed) Proc Symp Adv Mar Environ Res. EPA-600/9-79-035, US Environmental Protection Agency, Washington, DC, p 252-272

Wolk F, Yamazaki F, Seuront L, Lueck RG (2002) A new freefall profiler for measuring biophysical microstructure. J Atmos Ocean Tech 19:780-793

Wolk F, Seuront L, Yamazaki H, Leterme S (2004) Comparison of biological scale resolution from CTO and microstructure measurements. In: Seuront L, Strutton PG (eds) Scales in aquatic ecosystems: measurement, analysis, simulations. CRC Press, Boca Raton, FL, p 3-15

Wong CK, Ramcharan CW, Sprules WG (1986) Behavioral responses of a herbivorous copepod to the presence of other zooplankton. Can J Zool 64:1422-1425

Wu CH, Yang JS, Hwang JS (2004) Diet of three copepods in southern Taiwan Strait. Zool Stud 43:388-392

Wu KKS, Lahav O, Rees MJ (1999) The large-scale smoothness of the universe. Nature 397:225-230

Yamaguchi A, Watanabe Y, Ishida $\mathrm{H}$, Harimoto $\mathrm{T}$ and 5 others (2002) Community and trophic structures of pelagic copepods down to greater depths in the western subarctic Pacific (WEST-COSMIC). Deep-Sea Res I 49:1007-1025

Yen J (1988) Directionality and swimming speeds in predator-prey and male-female interactions of Euchaeta rimana, a subtropical marine copepod. Bull Mar Sci 43: 175-193

Yen J, Strickler JR (1996) Advertisement and concealment in the plankton: what makes a copepod hydrodynamically conspicuous? Invertebr Biol 115:191-205

Yen J, Weissburg MJ, Doall MH (1998) The fluid physics of signal perception by a mate-tracking copepod. Philos Trans R Soc Lond B 353:787-804

Yen J, Prusak AC, Caun M, Doall M, Brown J, Strickler JR (2004) Signaling during mating in the pelagic copepod Temora longicornis. In: Seuront L, Strutton PG (eds) Handbook of scaling methods in aquatic ecology: measurement, analysis, simulation. CRC Press, Boca Raton, FL, p 149-160

Young S, Getty C (1987) Visually guided feeding behavior in the filter feeding cladoceran, Daphnia magna. Anim Behav 35:541-548

Young S, Taylor VA (1990) Swimming tracks in swarms of two cladoceran species. Anim Behav 39:10-16

Submitted: April 7, 2004; Accepted: August 17, 2004

Proofs received from author(s): November 22, 2004 